\title{
Wind energy integration into future energy systems based on conventional plants - the Case Study of Croatia
}

\author{
Tin Cerovac, Boris Ćosić*, Tomislav Pukšec, Neven Duić \\ University of Zagreb, Faculty of Mechanical Engineering and Naval Architecture, Zagreb, Croatia \\ Department of Energy, Power Engineering and Environment \\ Ivana Lučića 5, 10002 Zagreb \\ Phone: +38516168242 , fax: +38516156940 \\ E-mail: boris.cosic@fsb.hr
}

\begin{abstract}
Croatian energy system is currently highly import-dependent and integration of a high share of renewable energy sources needs to be considered. This paper studies eight scenarios; three proposed by the Croatian Energy Strategy, one proposed by the Indicative medium-term development plan of Croatia's Transmission System Operator, and four alternative scenarios that propose extensive construction of hydro, wind and solar power plants in Croatia. Calculations have been conducted in the EnergyPLAN model based on modelled long term energy demand projections in the NeD model, with 2009 as the base year and a scope ranging until the year 2030. Each of the eight proposed scenarios is observed trough different hydrological conditions while analysing import dependency, economic costs and $\mathrm{CO}_{2}$ emissions. After the initial calculations, additional analysis of intensive wind power penetration has been conducted. The Results show that energy systems with a larger share of conventional and nonflexible power plants have more difficulty adjusting to wind power plants production. In case of a high share penetration of wind in a system based upon such power plants, the feasibility of investing in new large combustion plants that will spend most of the time working on minimum capacity is brought into question.
\end{abstract}

Keywords: EnergyPLAN model; NeD model; Large combustion plants; Intermittent renewable energy sources; Critical Excess Electricity Production (CEEP); Load Duration Curve (LDC)

\section{INTRODUCTION}

Growing dependency on energy imports, obligation to decrease $\mathrm{CO}_{2}$ emissions, high and unstable energy prices, and increasing age of production facilities are some of the problems European energy systems need to face. In 2010, primary energy import dependency of EU-27 countries amounted to $52.7 \%$, an increase of $22 \%$ since 1995 , with predictions of reaching $70 \%$ in the next 20-30 years [1]. To decrease import dependency, as well as reduce $\mathrm{CO}_{2}$ emissions, European Union is planning increased implementation of renewable energy sources (RES),

\footnotetext{
${ }^{*}$ Corresponding author
} 
setting the goals of producing 20\% of gross energy consumption from RES till 2020 [2] and $95 \%$ reduction of $\mathrm{CO}_{2}$ emissions from the energy sector until 2050 [3].

In order to increase RES implementation and reduce $\mathrm{CO}_{2}$ emissions, several different approaches have been studied by various papers. In article [4] several scenarios in order to reduce $\mathrm{CO}_{2}$ emissions in the UK by $60 \%$ till 2050 were considered. While some papers approach the problem in this way, considering the entire country [5], a number of them focus on small regions such as islands [6] and [7] and cities [8] and [9], as well as on particular sectors, such as energy [10], transport [11], residential [12] and industry, i.e. textile industry [13], steel industry [14] and cement industry [15]. Furthermore, some papers are going even further, exploring scenarios in order to achieve 100\% RES system. Such papers have been published studying cases of Denmark [16], Croatia [17], Portugal [18], Ireland [19] and Macedonia [20]. From all mentioned, we can conclude that a scenario approach is essential for successful planning of an energy system, as well as planning of long-term energy demand that has to be met by the system, explained in [21] and [22]. In that context, the implementation of RES has become an imperative after the RE-thinking 2050 [3].

RE-thinking 2050 also calls for phase-out of fossil fuels, and while some of the EU members, like Denmark, have already implemented this goal into their energy strategies by aiming towards a 100\% RES system [23], some of the member countries haven't yet updated their energy strategies till 2050. However these energy strategies, such as German [24], Ireland [25], UK [26] and Portugal [27] still give a great emphasis on RES implementation. Significant implementation of RES has already begun - in 2008 more plants using renewable than conventional energy sources have been built, capacity-wise. Out of $23.8 \mathrm{GW}$ of new power plant capacities, renewable energy sources accounted for 57\%. Among the RES technologies used, wind power plants are leading by far. They have accounted for $39 \%$ of total installed power plants in 2009 , followed by natural gas at $25 \%$ and solar power plants with $17 \%$ of total installed capacities [3]. Due to rapid growth and intermittent nature of wind and solar energy forecasting reliability of these systems will become prime concern [28]. Furthermore, the unstable characteristics of renewable energy sources leads to increase use in storage technologies such as pump hydro storage [17], compressed air energy storage (CAES) [29], electric vehicles [30] and batteries [31] for balancing electricity demand and supply.

In the case of Croatia, the Energy Strategy [32] acknowledges the need of RES implementation, with some projects already being realized [33], but there still remains much to be done in order to achieve goals set for the year 2020. Furthermore, the Croatian Energy Strategy predicts phase-out of all present thermal power plants which use coal and heavy fuel oil until 2030. In the case of hydro power plants, special attention must be given to hydrology since $51 \%$ of Croatia's energy production in 2009 came from large hydro power plants [34], with the yearly production in the last decade ranging from $39.4 \%$ in 2007 to $62.7 \%$ in 2010 of total energy production [35].

The purpose of this paper is to present a possible solution for development of future energy model for Croatia, taking into account future energy consumption, and to analyze implications 
of integrating a high share of intermittent renewable energy sources into future energy scenarios. First, a reference model for the year 2009 was created and future energy demand of Croatia in the years 2020 and 2030 has been calculated with NeD model. After creating the reference model, the models of eight future scenarios in the years 2020 and 2030 were developed and observed through different hydrological conditions while analyzing electricity import, environmental and economic aspects. Three of those scenarios were proposed by the Croatian Energy Strategy [32], one was proposed by the Indicative medium-term development plan of Croatia's Transmission System Operator (TSO) [36], and four were alternative scenarios that propose extensive construction of hydro, wind and solar power plants in Croatia. Finally, the impact of increased wind power production on critical excess electricity production, electricity import and load duration curves for condensing power plants in scenarios featuring extensive conventional power plants implementation were analysed, thus highlighting advantages and disadvantages of proposed scenarios.

\section{METHODOLOGY}

\subsection{EnergyPLAN model}

In order to analyze and compare proposed scenarios, freeware EnergyPLAN model [37] has been selected. One of its advantages is its emphasis on renewable energy sources and their integration into existing systems. For example, the Chinese energy system was reconstructed in EnergyPLAN in paper [38]; a study of large-scale integration of wind power, phase-out of nuclear energy while increasing the share of RES in the case of Romania was analyzed in [39]; reduction of GHG emissions in the US using photovoltaic (PV) was studied in [40]; implementation of combined heat and power (CHP) plants was studied in [41], etc. As shown in the aforementioned papers, the model uses input data and conducts annual analysis of an energy system based on hourly steps.

Some of the input data used by the model are electricity and heat demands, installed capacities and technologies, fuel consumption divided by sectors, cost of fuel, investments and $\mathrm{CO}_{2}$ emissions, operation and maintenance costs. Several regulation and optimization strategies, hourly curves describing various productions, import, export, market price changes, etc. are used, while allowing the user to set transfer capacities for the system allowing import and export of electricity. Results of the model analysis are electricity production, import and export along with their cost and gain respectively, emissions of $\mathrm{CO}_{2}$ along with their breakdowns by technologies, expressed as annual, monthly or hourly values.

These results are greatly depending on the selected regulation strategy. Two main regulation strategies offered by the model are technical and market regulation. The first one focuses on satisfying the given heat demand or both heat and electricity demand. It balances production from RES, hydro power plants, CHP, condensing, nuclear and other power plants in order to achieve given heat and electricity demand, while at the same time seeking to avoid or minimize critical excess electricity production (CEEP). CEEP is the amount of excess electricity produced that could not be used in the energy system or exported and it can lead to frequency changes and grid collapse. EnergyPLAN labels such energy as critical excess electricity 
production or CEEP. The market regulation option uses fuel prices, as well as market costs of electricity, in order to determine marginal production costs, and then determines optimum use of system components from an economic point of view. Detailed information about behaviour and technology preferences for both regulation options are explained in the model's manual [42].

\subsection{Future energy demand}

Since the primary goal of an energy system is to satisfy the demand, long-term projections have to be made in order to properly design the future system.

Long-term projections used in this paper were modelled using the "bottom up" methodology, starting from the end-consumer of energy. Analysis and projections were based upon sector system approach in order to achieve better predictions of future energy demand. For the purposes of calculating long term energy demand NeD model was used [43]. This kind of approach demands a significant amount of information and a specific approach to each sector in order to accurately describe the mechanisms and parameters affecting the consumption in the sector, thus providing more accurate results. Referent year is used to calibrate and test the long term energy demand forecast methodology. That way all input information are checked and unknown components are determined, e.g. specific consumptions, various coefficients, etc. In order to use calculated data for system planning, it is necessary to convert the results from useful to final energy demand. This is achieved by combining data on various types of technologies and their efficiencies.

Future energy demand projections of Croatian sectors, using specific input data, have been studied in several papers. For instance, in case of the housing sector, described in [22], floor surfaces were combined with climate data and building characteristics, calculating the need for heating and cooling and achieving final energy demand by applying various technologies and efficiencies. Similar approach can be applied to educational sector, adding parameters such as number of students, classes and school year lengths, etc., as described in [44]. The touristcatering trade sector, as analyzed in [21], studied the influence of total accommodation, length of the tourist season, number of tourists and other specific data before using the same technique to calculate final energy demand. When calculating the transport sector, total number of vehicles, their fuel mix, fuel consumptions, vehicle life span and other factors were taken into consideration when calculating final demand, as described in [45]. The most complex approach was used when studying the industry sector, with sub-sector analysis based on the products' specific energy value, as well as their variations, as described in [46].

Sector specific approach provides more accurate data from each sector, providing more accurate results after combining them. Combining of calculated specific sector data into a national case scenario has been described in [47]. The results of the aforementioned sectors will provide future energy demands, described trough various scenarios, which shall provide the data necessary to design the national energy system. 


\section{SCENARIO APPROACH: THE CROATIAN ENERGY SYSTEM}

\subsection{Referent energy system}

In order to compare the scenarios, a base year has been set as 2009 and modelled in EnergyPLAN. Information regarding electrical and heat demands has been acquired from [34], while hourly curves describing various loads have been constructed using data from [35]. Input data regarding technology mix and their efficiencies has been acquired from [34] and from Croatian national electricity company (HEP Group) [48]. Further information, regarding civil, industrial and transport sectors, has been acquired from [49]. After setting the aforementioned production parameters for the energy system, attention had to be given to import and export of electricity since imported electricity covered $41 \%$ of the total domestic supply in 2009 [35]. Total cross border capacity for import and export has been set to $3200 \mathrm{MW}$ according to [50] while the production from the nuclear power plant in Krško, Slovenia, has been modelled as a constant import.

The initial technical regulation balancing both heat and electricity demands has been subsequently replaced by market regulation because of the heavy fuel oil powered thermal power plants in Croatia which, despite their large capacity, have relatively small number of working hours per year [34] thus preventing the model from generating a valid representation of Croatia's energy system using technical regulation. Use of the market regulation approach requires additional curves and electricity market prices, which have been modelled as described in [17], and gives the benefit of better electricity exchange modelling while solving the problem of unfeasible fuel oil powered plants.

The described model has been compared with available data regarding electricity and heat production [34], $\mathrm{CO}_{2}$ emissions, shares of particular technologies in total production as well as electricity exchange [48] to determine if the proposed base scenario is a valid representation of the Croatian energy system in 2009.

\subsection{Energy scenarios}

After a valid representation of the Croatian energy system has been established, a total of eight scenarios describing different development paths for the system until the year 2030 have been studied. The Croatian Energy Strategy predicts that until 2030, most of Croatia's thermal power plants (TPP) currently in operation will be phased-out [32], and replacements for them must be made. Furthermore, all of the hydro power plants currently in operation shall remain in the system, and all scheduled commissioning dates in [32] and [36] have been set back three years, approximated from the current state of realization [33] and [48], and all new power plants shall have a 5\% lower specific fuel consumption accounting for the new equipment and technologies used.

- First three of the total eight scenarios used in this paper have been designed according to the Croatian Energy Strategy [32]. They are named the Blue, the White and the Green scenario to correspond to the scenarios in the Croatian Energy Strategy. They can be summarized by the information provided in Table 1 . 
Table 1 - Scenario data from the Croatian Energy Strategy [32].

\begin{tabular}{|l|}
\hline BLUE SCENARIO (2 natural gas TPP, 2 coal TPP) \\
\hline - 2013: commissioning of a natural gas powered thermal power plant $-400 \mathrm{MW}$ \\
- 2015: commissioning of a coal powered thermal power plant $-600 \mathrm{MW}$ \\
- 2019: commissioning of a coal powered thermal power plant $-600 \mathrm{MW}$ \\
- 2020: commissioning of a natural gas powered thermal power plant $-400 \mathrm{MW}$ \\
\hline GREEN SCENARIO (2 natural gas TPP, 1 nuclear power plant (NPP)) \\
\hline - 2013: commissioning of a natural gas powered thermal power plant $-400 \mathrm{MW}$ \\
- 2015: commissioning of a natural gas powered thermal power plant $-400 \mathrm{MW}$ \\
- 2020: commissioning of a nuclear power plant - $1000 \mathrm{MW}$ \\
\hline WHITE SCENARIO (1 natural gas TPP, 1 coal TPP, $1 \mathrm{NPP})$ \\
\hline - 2013: commissioning of a natural gas powered thermal power plant $-400 \mathrm{MW}$ \\
- 2015: commissioning of a coal powered thermal power plant $-600 \mathrm{MW}$ \\
- 2020: commissioning of a nuclear power plant $-1000 \mathrm{MW}$
\end{tabular}

Next three scenarios are developed according to data from the Croatian Energy Strategy [32], Registry of renewable energy sources [33] and from [51].

- Scenario number four, "Wind" scenario, assumes installation of $1.2 \mathrm{GW}$ of wind power plants until 2020, with further $800 \mathrm{MW}$ installed by 2030 .

- Scenario number five, "Hydro" scenario, proposes extensive building of hydro power plants, according to [51], in the total amount of $386 \mathrm{MW}$, through a period described in Table 2, and all projects from registry of RES in Croatia [33], latter being divided 29 MW by the year 2020 and further 100 MW by the year 2030 .

Table 2 - Commissions of hydro power plants in Croatia [51].

\begin{tabular}{||c|c|c|c|c|c||}
\hline \multirow{2}{*}{$\begin{array}{c}\text { Hydro power } \\
\text { plant }\end{array}$} & $\begin{array}{c}\text { Installed capacity } \\
(\mathrm{MW})\end{array}$ & Predicted annual & \multicolumn{3}{|c|}{$\begin{array}{c}\text { Commission } \\
\text { timeframes }\end{array}$} \\
\cline { 4 - 6 } & & production $(\mathrm{GWh})$ & 1 & $\mathbf{2}$ & 3 \\
\hline Novo Virje & 140 & 650 & 2030. & $\mathbf{2 0 1 2}$. & 2012. \\
\hline Podsused & 44 & 215 & & $\mathbf{2 0 0 6}$. & 2006. \\
\hline Drenje & 39 & 185 & & $\mathbf{2 0 0 9}$. & 2009. \\
\hline Lešće & 40 & 94 & 2020. & $\mathbf{2 0 1 8}$. & 2018. \\
\hline Ombla & 63 & 172 & & $\mathbf{2 0 2 1}$. & \\
\hline Krčić & 7,6 & 37 & & $\mathbf{2 0 1 5}$. & 2015. \\
\hline Kosinj & 52 & 265 & & \\
\hline
\end{tabular}

- Scenario number six, "RES" scenario, provides a mix of various renewable energy sources to be implemented into the system, adding 1.2 GW of wind, $400 \mathrm{MW}$ of hydro 
power plants, and $45 \mathrm{MW}$ of PV by the year 2020, and further $800 \mathrm{MW}$ of wind, 40 MW of hydro power plants, and 205 MW of PV by the year 2030 [33].

- Scenario number seven, "Replacement" scenario, proposes substitution of decommissioned thermal power plants with power plants of equal capacity and using the same fuel, except in the case of heavy fuel oil, which shall be phased-out and substituted with natural gas powered thermal power plants. All of the plants will have lower fuel consumption, as stated earlier, and their commission dates will be corresponded with their decommission date. Decommission dates are given by the Croatian Energy Strategy, as described in Table 3.

Table 3 - Decommission of thermal power plants in Croatia [32].

\begin{tabular}{|l|c|c|c|}
\hline \multicolumn{1}{|c|}{ Power plant } & $\begin{array}{c}\text { Nominal power } \\
(\mathrm{MW})\end{array}$ & $\begin{array}{c}\text { Threshold capacity } \\
(\mathrm{MW})\end{array}$ & $\begin{array}{c}\text { Year of } \\
\text { decommission }\end{array}$ \\
\hline EL-TO Zagreb A & 12.5 & $(9)$ & 2011 \\
\hline TE Sisak A & 210 & $(198)$ & 2013 \\
\hline TE Plomin A & 105 & $(93)$ & 2015 \\
\hline TE-TO Osijek A & 25 & $(23,5)$ & 2017 \\
\hline TE-TO Osijek B & 25 & $(23,5)$ & 2017 \\
\hline KTE Jertovec A & 42.5 & $(37)$ & 2018 \\
\hline KTE Jertovec B & 42.5 & $(37)$ & 2018 \\
\hline TE-TO Zagreb C & 110 & & 2019 \\
\hline TE-TO Osijek A & 45 & $(42)$ & 2019 \\
\hline TE Sisak B & 210 & $(198)$ & 2019 \\
\hline EL-TO Zagreb B & 32 & $(26)$ & 2019 \\
\hline TE Rijeka & 320 & $(303)$ & 2025 \\
\hline EL-TO Zagreb A & 25.6 & & 2025 \\
\hline EL-TO Zagreb B & 25.6 & & 2030 \\
\hline TE-TO Zagreb K & 210 & & \\
\hline
\end{tabular}

- Last scenario proposed by this paper, "Slowed build" scenario, deals with the slow construction of new power plants, as described by the middle-term strategy of Croatian TSO [36]. In this scenario $230 \mathrm{MW}$ of natural gas powered CHP plants and $300 \mathrm{MW}$ of wind power plants until 2020 and further $300 \mathrm{MW}$ of wind and $82 \mathrm{MW}$ of hydro power plants until 2030 will be installed.

\subsection{Hydrological conditions}

Historical climate and hydrological data [35] have been used to create EnergyPLAN curves for cases of dry, wet and average hydrological conditions. Since the production from hydro power plants in the base year deviated from the average production in the last decade by only $0.05 \%$, base year production of 6.337 TWh has been used to model the average curve. The wet curve 
has been modelled to achieve the maximum production of the last decade, $8.313 \mathrm{TWh}$, and the dry curve has been modelled according to the lowest production of $4.361 \mathrm{TWh}$. Due to the nature of EnergyPLAN model's calculations, it is possible to add new power plants to the system and calculate new production from hydro power plants using the same curves as with the original system.

\subsection{Increased implementation of wind power plants}

In order to study the impact of wind power plants on the system, critical excess electricity production and electricity import have been analyzed. Electricity import has been selected as a studied parameter since it should provide information on how well the system copes with demand, i.e. how does increased wind penetration affect on electricity production. It is to be expected that increased capacities should lead to increased production, thus lowering import. At the same time, if the new capacities satisfy the demand, electricity excess could occur. Studying the impact of increased wind power on CEEP should describe how much wind capacities can be installed in the system without compromising it, and how will the system react to them.

Electricity import and CEEP have been calculated using serial calculations. Serial calculation is an option offered by EnergyPLAN which enables the user to obtain values of a certain output parameter for the given scenario, such as CEEP and electricity import in this case, depending on a single varying input parameter, in this case - installed wind power plant capacity. Serial calculations have been conducted for all scenarios and sub-scenarios and the years 2020 and 2030 .

Furthermore, load duration curves (LDC) for production from condensing power plants have been analyzed. A load duration curve, a diagram depicting number of annual hours spent working at a certain load, should describe how condensing power plants, using conventional technologies, shall react to wind power implementation, i.e. how will their annual work hours be affected by large quantities of intermittent energy sources. Analysis will be conducted only on the four scenarios that feature extensive implementation of conventional power plants "Blue", "White", "Green" and "Replacement" scenario. Also, the calculations will focus on the normal hydrological conditions for the year 2020 and 2030 while not exceeding $50 \%$ of total energy demand covered from wind power.

\section{RESULTS}

Analysis in the EnergyPLAN model was conducted for closed and open energy system. In the case of open energy system transfer capacities previously set are used to exchange electricity and at the same time to reduce CEEP, while in the case of closed energy system exchange capacities with neighbouring countries are set to zero. Results on future energy demand, impact of high share wind penetration and influence of the hydrology in the year 2020 and 2030 have been calculated and presented in this section.

\subsection{Future energy demand}


Meeting the energy demand is the primary purpose of any energy system, and thus becomes one of the most important questions when analyzing scenario results. Future energy demand has been calculated as described in [21], [22] and [44] and then combined into a national energy demand projection, according to [43] and [47], whose results are shown in Figure 1.

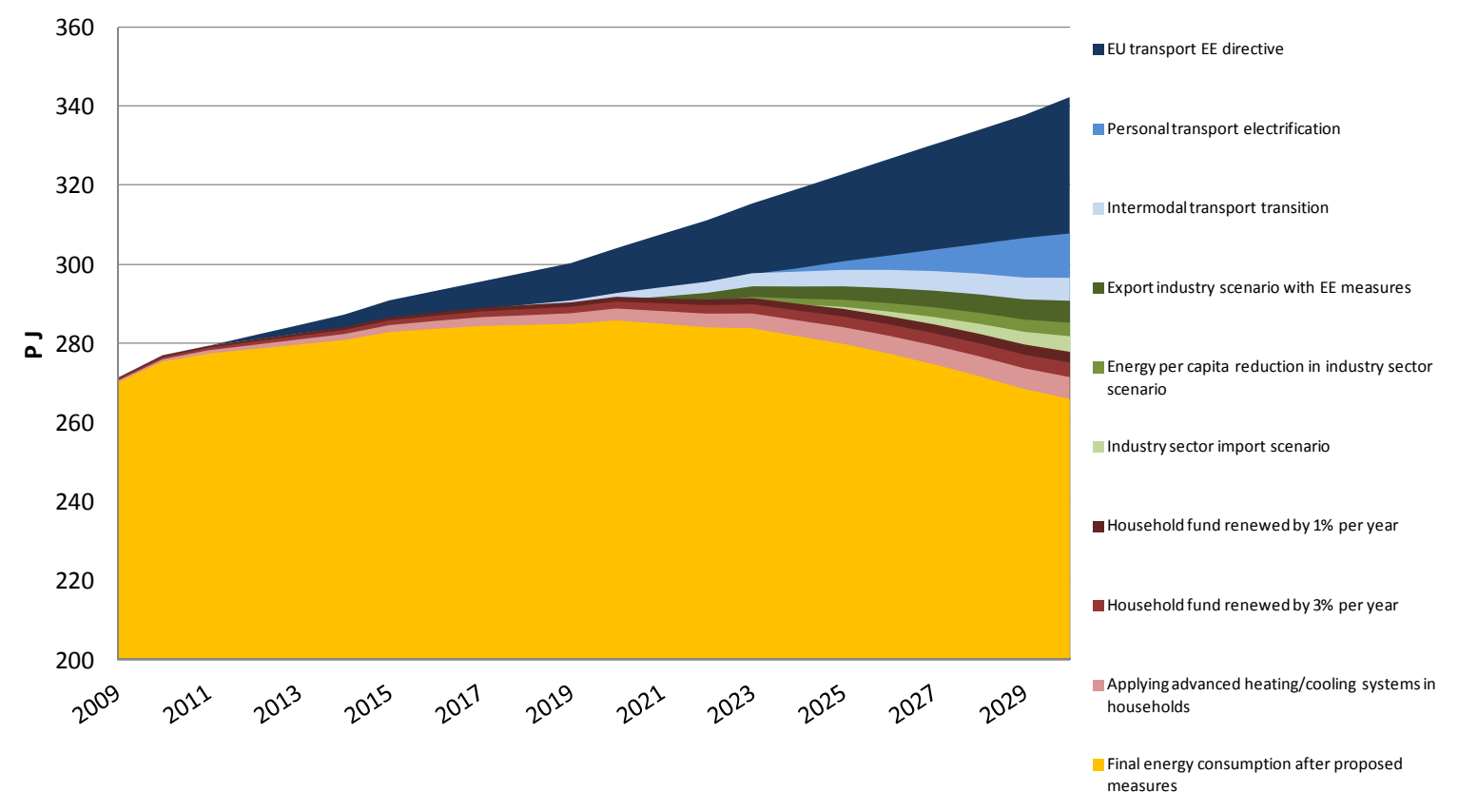

Figure 1 - Future energy demand after energy saving measures, in PJ.

Several energy saving scenarios that would influence future energy demand of industry, transport, households and other sectors were proposed and described in [47]. After their application, final energy demand until the year 2030 has been calculated and it will be used as the energy demand for further calculations. Energy demand after energy saving measures, divided by sectors, is shown in Figure 2. 


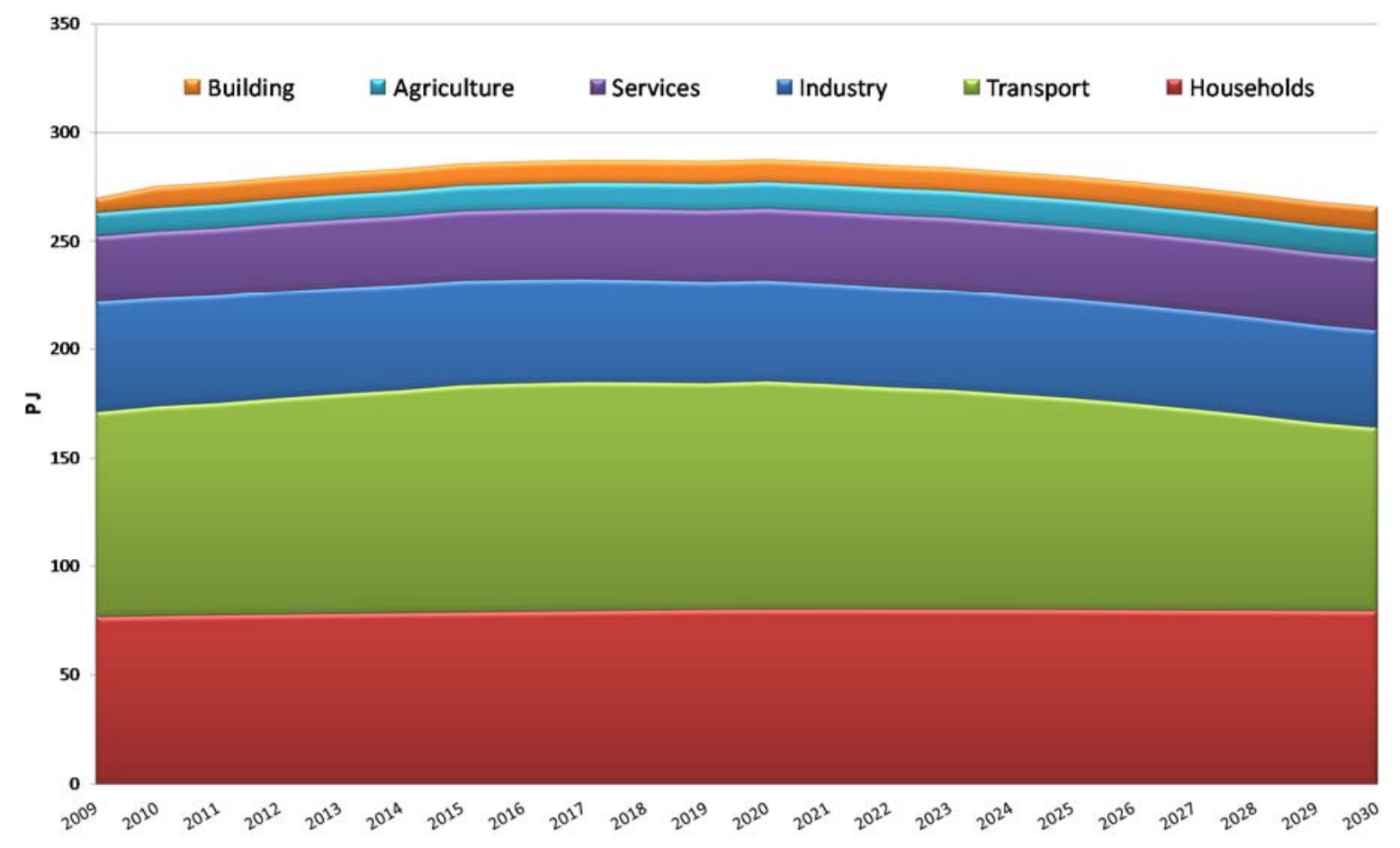

Figure 2 - Future energy demand after energy saving measures for various sectors, in PJ.

Calculated results have been used to complete scenario data and calculate necessary wind power plant capacities for serial calculations.

\subsection{Scenario analysis}

After calculating the future energy demand, scenario and hydrology input data could be completed and fed into the EnergyPLAN model. Obtained results will be divided into three categories - electricity import, environmental and economic impact,

\subsubsection{Electricity import}

The amount of imported electricity will be an indicator of how successfully the system proposed by a scenario has met the demand, since the demand for electrical energy must be met, and all electricity that has not been produced in the country must be imported. Results for the first period, shown in Figure 3, indicate that systems featuring a larger share of conventional energy sources cover the demand for electricity more successfully. 
Electricity import in TWh/y, year 2020.

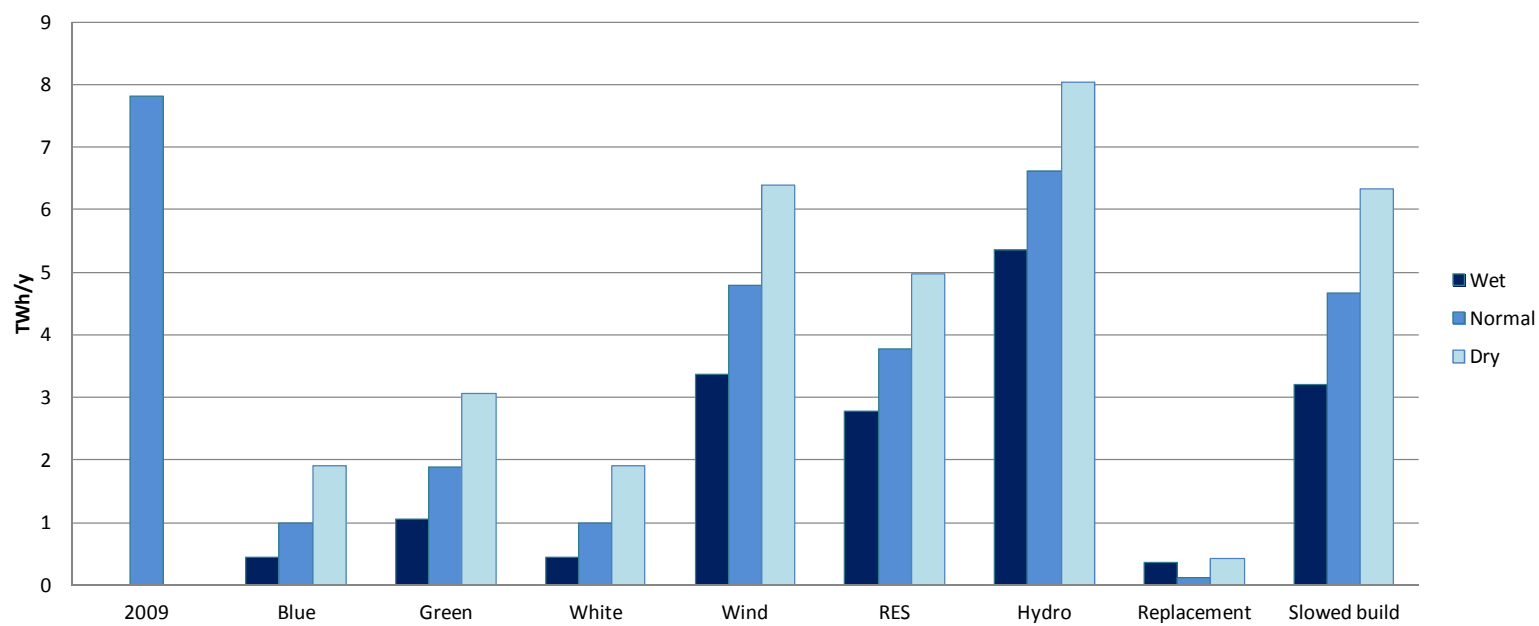

Figure 3 - Calculated import of electricity in $\mathrm{TWh} / \mathrm{y}$ for different scenarios and hydrological conditions in 2020.

Starting at $42.36 \%$ of total electricity demand, or $7.82 \mathrm{TWh}$, imported in 2009 , largest import has occurred in the case of "Hydro" scenario, with $66.05 \%$ of total energy demand covered by import in the case of a dry hydrological condition in the second period, following decommission of Krško nuclear power plant. At the same time, lowest import is achieved in "Replacement" scenario, at just $0.6 \%$ of the total energy production. This can be explained by the replacement of non working heavy fuel oil power plants with natural gas power plants, whose cheaper fuel enables greater usage under the market regulation model, as well as the fact that this result is achieved in the first time period, with Krško still in operation.

In the period after 2020, shown in Figure 4, when the decommission of Krško nuclear power plant occurs, all scenarios experience an increase of import, except in the case of "White" and "Green" scenarios where the power plant is replaced with a nuclear power plant of even larger capacity and thus reduces the import dependency to $0.3 \%$ of electricity demand. While "RES" scenario shows a decrease in import dependency in the first period, after decommission of Krško, import dependency is doubled. With "RES" scenario being approximately in the same price range as "White" (4.57 billion euro, given the use of nuclear technology), this indicates the difficulty of RES implementation in systems that incorporate nuclear power phase-out or decommission, as seen in [39]. 
Electricity import in TWh/y, year 2030.

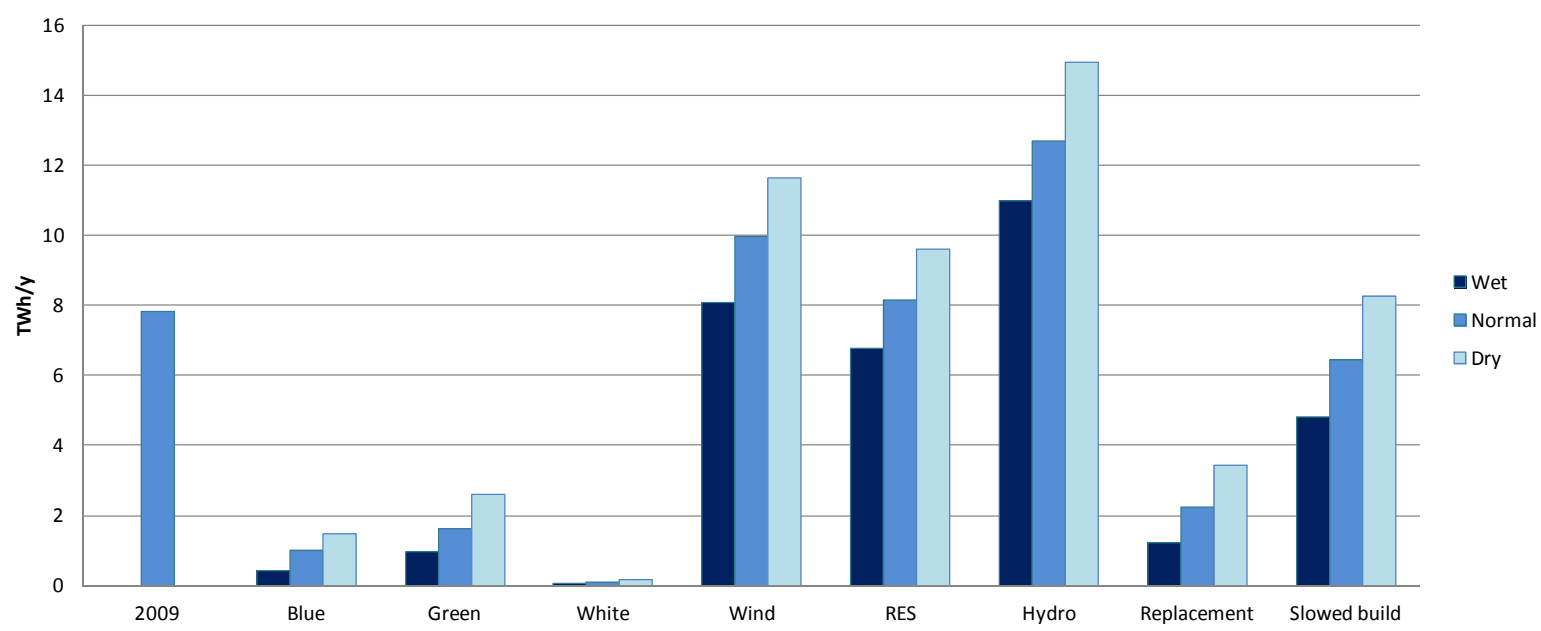

Figure 4 - Calculated import of electricity in $\mathrm{TWh} / \mathrm{y}$ for different scenarios and hydrological conditions in 2030 .

\subsubsection{Environmental impact}

Environmental impact of each scenario will be observed through $\mathrm{CO}_{2}$ emissions. According to available information [34] and [49], emission of $\mathrm{CO}_{2}$ in the base year amounted to 19.487 Mt.

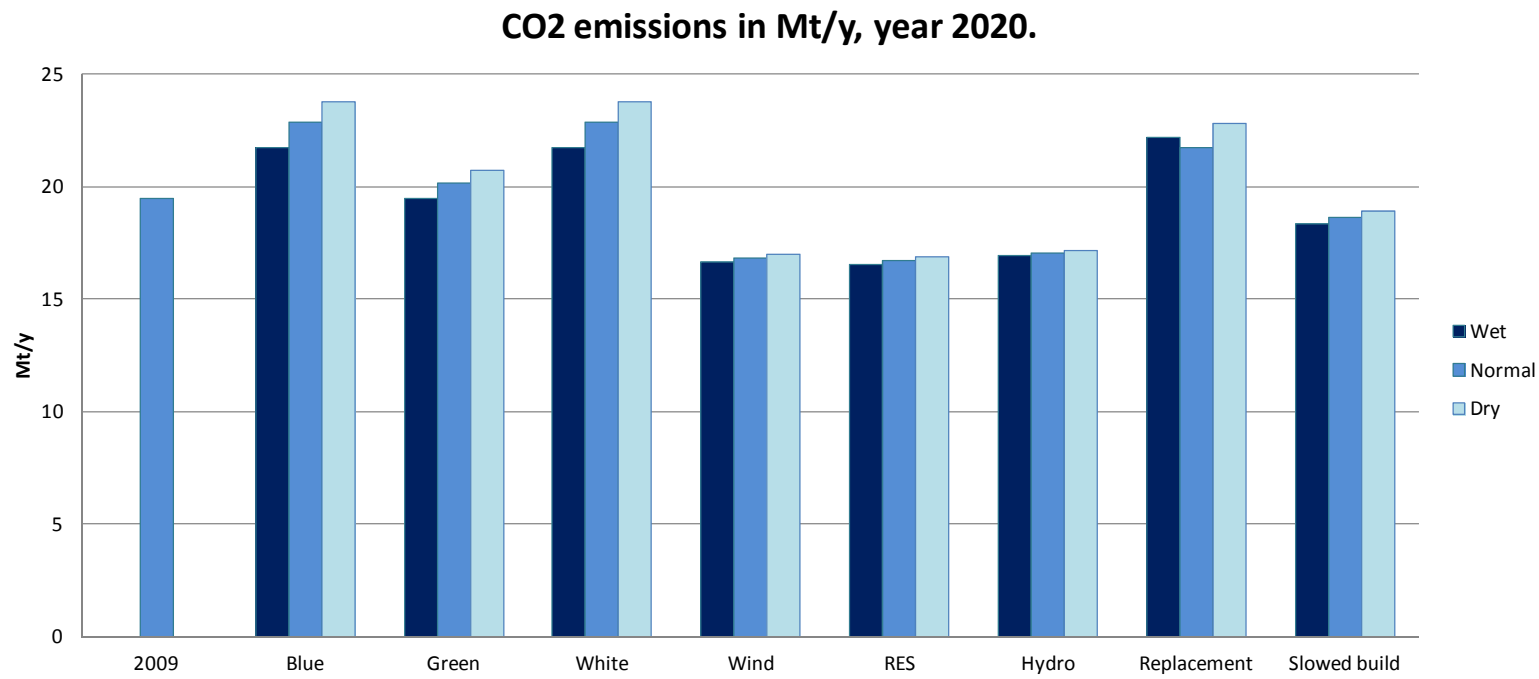

Figure 5 - Calculated $\mathrm{CO}_{2}$ emissions for different scenarios and hydrological conditions in 2020 


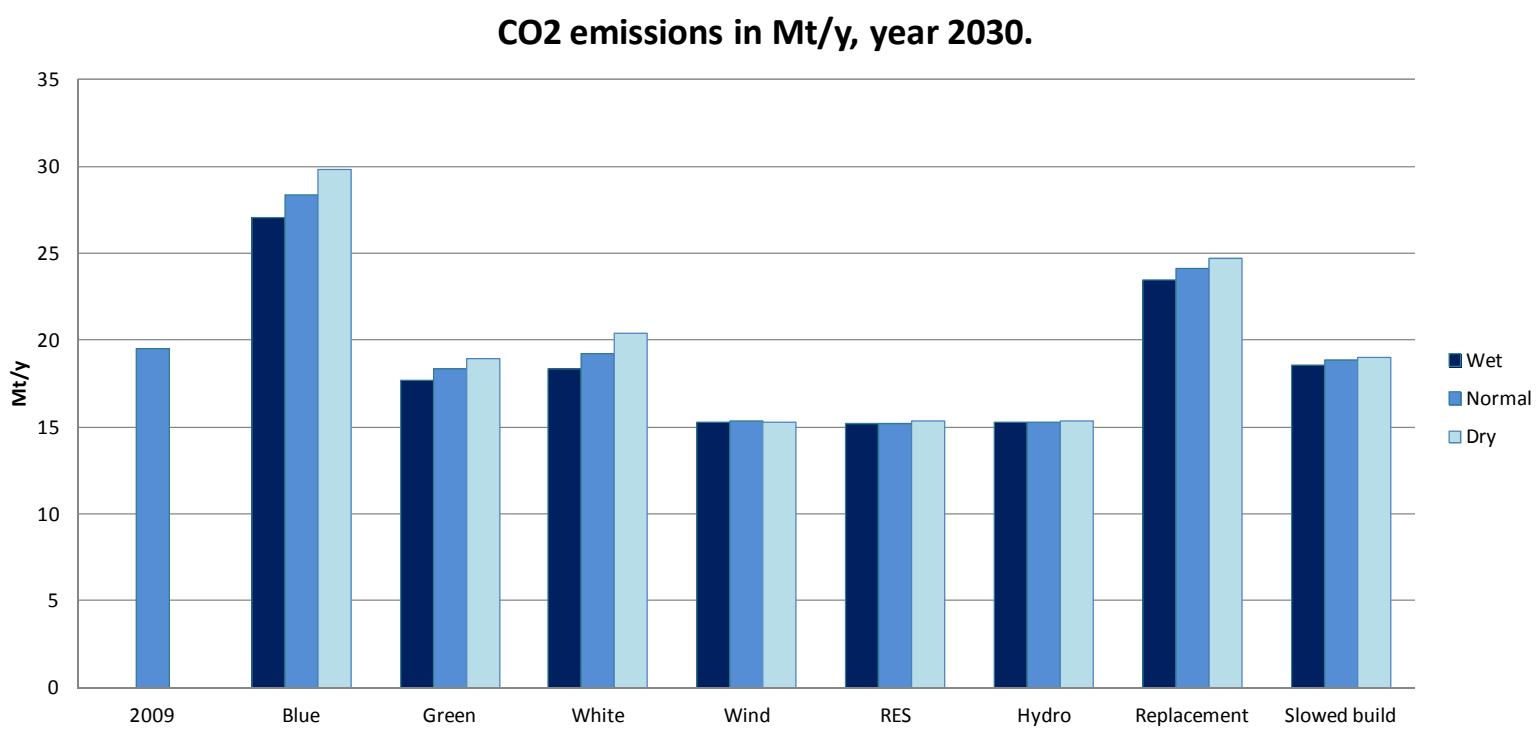

Figure 6 - Calculated $\mathrm{CO}_{2}$ emissions for different scenarios and hydrological conditions in 2030 .

Results in Figure 5 and Figure 6 show a decrease in $\mathrm{CO}_{2}$ emissions in scenarios featuring a significant amount of RES implementation. In the case of scenarios with large fossil fuels plants, increases in $\mathrm{CO}_{2}$ emissions have occurred.

In the first period and normal hydrological condition, largest growth of emissions is seen in the "Blue" scenario with $17.2 \%$ increase from the base year value in the second period. Other Green book scenarios show a growth tendency of $17.2 \%$ in case of "White" scenario, and about 3.3\% in the case of "Green" scenario. In the second period, both "Green" and "White" scenario experience a drop of $\mathrm{CO}_{2}$ emissions due to the commission of the planned nuclear power plant, while the "Blue" scenario continues to show growth and reaches the maximum emission value of all scenarios in case of dry hydrological condition - 53.1\% increase from the base year emission value. Meanwhile, RES implementing scenarios show a decrease of emissions in both studied periods. All three of them achieve a similar decrease, which is the largest in the case of "RES" scenario, $14-16 \%$ in the first and $21.3-22.2 \%$ in the second studied time period. As expected, implementation of renewable energy sources greatly decreases $\mathrm{CO}_{2}$ emissions and the costs associated with them.

\subsubsection{Economic evaluation of scenarios}

In this section the results of analysis for annual operating costs in eight studied scenarios were presented. For this analysis, fuel price and $\mathrm{CO}_{2}$ content in the fuels from [20] and $\mathrm{CO}_{2}$ price of $25 € / \mathrm{t}$ [20] for the year 2020 and $45 € / \mathrm{t}$ [3] in the year 2030, have been used. Investment costs, operating and maintaining costs (O\&M) for large combustion plants, nuclear plants and RES technologies were obtained from Danish Energy authority [52], Croatian Ministry of Economy [34] and from [17] and [20]. The discount rate of 12\% and the economic lifetime of 20 years for wind and solar and 30 years for large conventional plants were used to determinate the annual operating costs of analyzed scenarios [52] and [53]. Total annual operating costs for 
eight scenarios and normal hydrology are presented on Figure 7 for the year 2020 and on Figure 8 for the year 2030

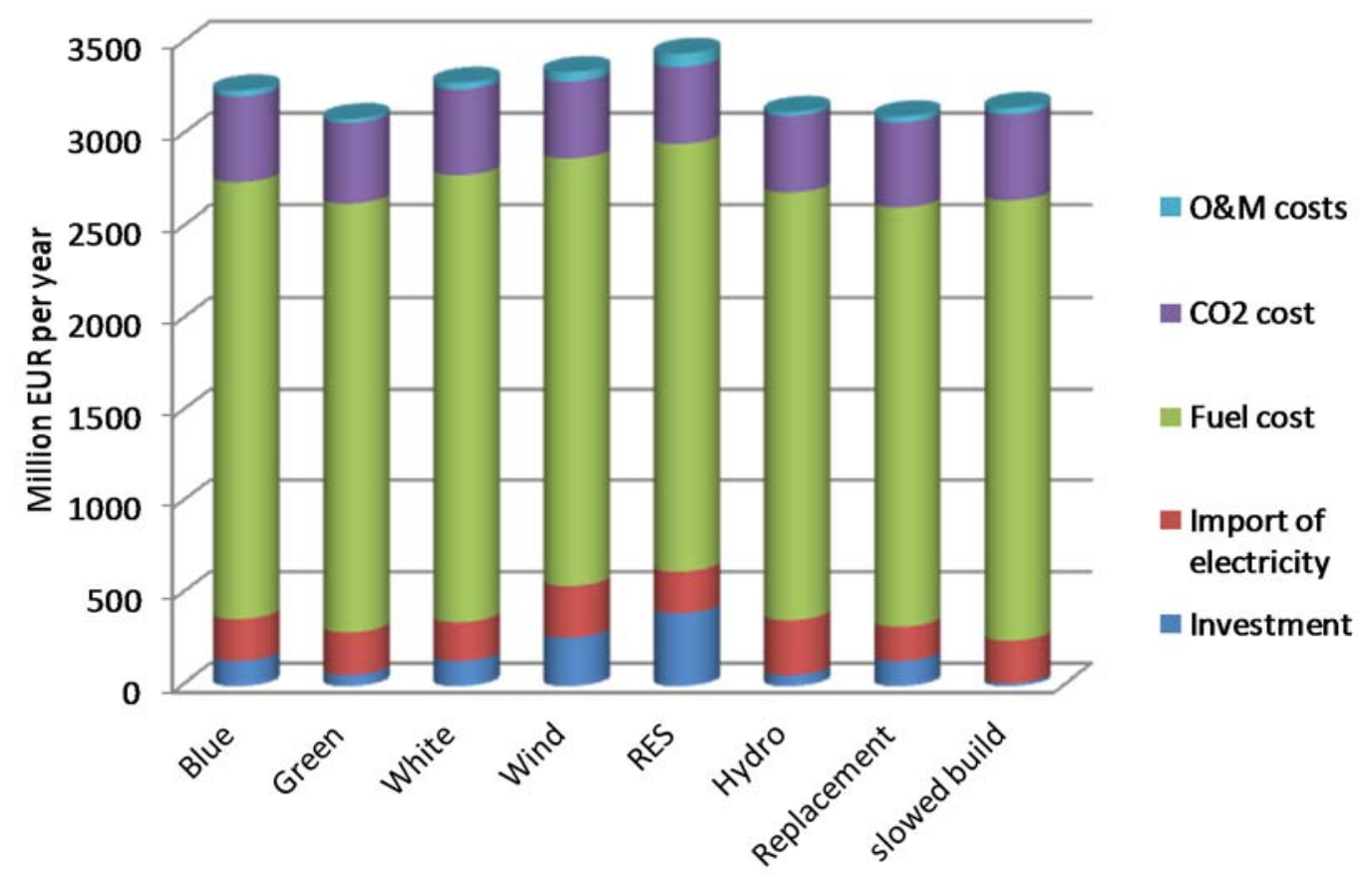

Figure 7 - Annual operating costs of the various scenarios in the year 2020, normal hydrology.

Resultes on Figure 7 shows that highest annual investments costs of 394 M€ have "RES" scenario while highest fuel costs have "white" scenario. In the case of import of electricity, the highest import have "Hydro" scenario while lowest import is occured in "Replacment" scenario.

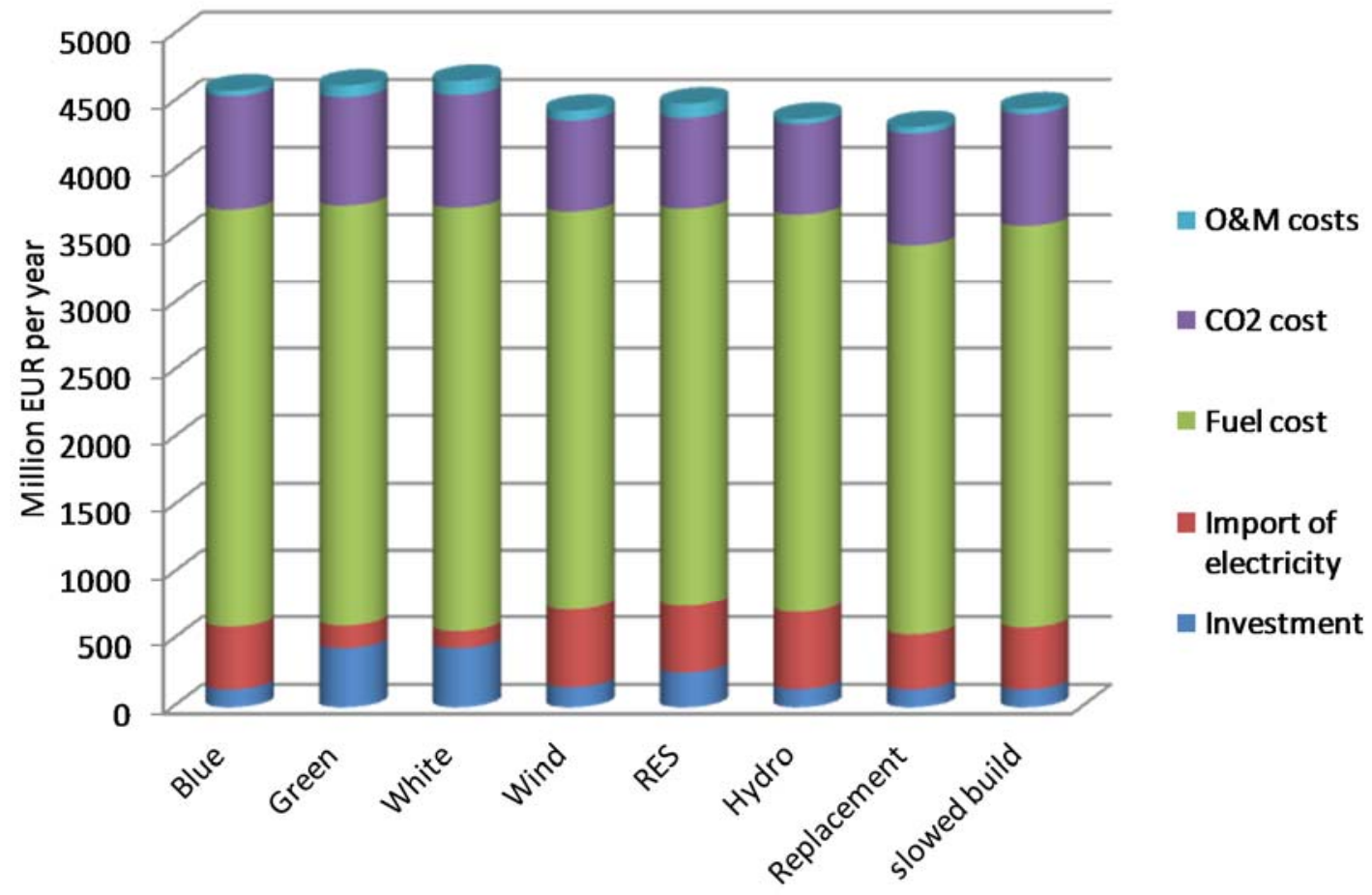


Figure 8 - Annual operating costs of the various scenarios in the year 2030, normal hydrology.

In the year 2030, the highest annual investment costs of $435 \mathrm{M} €$ have "Green" and "White" scenario due to construction of nuclear power plants. Furthermore, the highest import of electricity is occurred in the "Wind" and "RES" scenarios while the highest $\mathrm{CO}_{2}$ emissions cost of $830 \mathrm{M} €$ have scenarios with large combustion plants, such as "Blue", "Green", "White", "Replacement" and "Slowed build".

\subsection{Impact of wind power on energy system}

In the context of increasing RES implementation, it is important to study the impact of increasing wind capacities, as the leading RES technology today, on the planned system because of its intermittent nature. For that purpose, serial calculations varying the amount of installed wind capacities have been conducted while studying CEEP and electricity import for all scenarios and LDC of condensing power plants for scenarios features extensive implementation of conventional energy sources. In order to run serial calculations, amounts of installed wind capacities necessary to cover a certain percentage of electricity demand in the studied year had to be determined. Their capacities have been determined according to the desired percentage of electricity demand and the results are given in Table 4.

Table 4 - Estimated wind power plant capacities needed to cover various percentages of total electricity demand in 2020 and 2030.

\begin{tabular}{|l|c|c|c|c|c|c|c|c|c|c|}
\hline $2020-19.83 \mathrm{TWh}$ & $10 \%$ & $20 \%$ & $30 \%$ & $40 \%$ & $50 \%$ & $60 \%$ & $70 \%$ & $80 \%$ & $90 \%$ & $100 \%$ \\
\hline Demand (TWh) & 1.98 & 3.96 & 5.95 & 7.93 & 9.92 & 11.90 & 13.88 & 15.87 & 17.85 & 19.83 \\
\hline $\begin{array}{l}\text { Matching capacity } \\
\text { (MW) }\end{array}$ & 832 & 1664 & 2496 & 3329 & 4161 & 4993 & 5826 & 6658 & 7490 & 8322 \\
\hline $2030-22.60 \mathrm{TWh}$ & $10 \%$ & $20 \%$ & $30 \%$ & $40 \%$ & $50 \%$ & $60 \%$ & $70 \%$ & $80 \%$ & $90 \%$ & $100 \%$ \\
\hline Demand (TWh) & 2.26 & 4.52 & 6.78 & 9.04 & 11.30 & 13.56 & 15.82 & 18.08 & 20.34 & 22.60 \\
\hline $\begin{array}{l}\text { Matching capacity } \\
\text { (MW) }\end{array}$ & 948 & 1896 & 2844 & 3793 & 4741 & 5689 & 6638 & 7586 & 8534 & 9482 \\
\hline
\end{tabular}

\subsubsection{Critical excess electricity production - CEEP}

Critical excess electricity production has been calculated for open as well as closed energy systems. In the case of closed energy systems, transport capacities between neighboring countries were set to zero, while in the case of open systems capacity of transmission lines were set to $3200 \mathrm{MW}$. The closed energy system represents the worst case scenario in terms of CEEP since it depicts a situation in which the neighboring systems experience saturation in the exact same times as the studied system, thus being unable to accept the excess energy.

Dependence of CEEP on the percentage of total energy demand covered by wind power for all of the scenarios and normal hydrological condition in the year 2020 can be seen in Figure 9. 


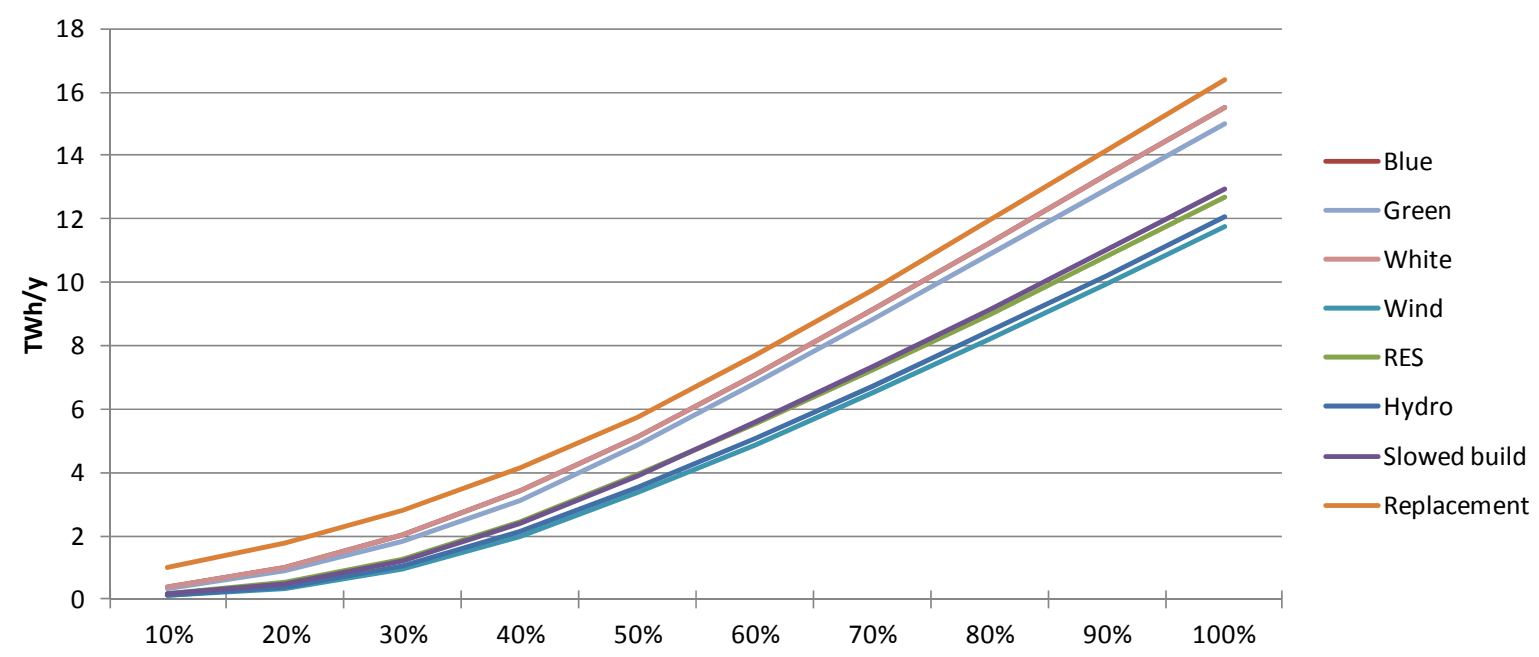

Figure 9 - Calculated CEEP for all scenarios and normal hydrology in 2020.

It can be seen that conventional scenarios experience significant amounts of CEEP with only $10 \%$ of the demand covered with wind energy, while scenarios featuring a greater share of RES also experience CEEP, but in smaller amounts, that could probably be regulated by using exchange capacities. As expected, the amount of CEEP grows as more of the demand is covered by wind energy. Results presented in Table 5 for other hydrological conditions follow the same patterns shown in Figure 9, but with different absolute values.

Table 5 - Calculated CEEP for different scenarios and hydrological conditions in 2020.

\begin{tabular}{|c|c|c|c|c|c|c|c|c|c|c|c|}
\hline \multicolumn{2}{|c|}{2020} & \multicolumn{10}{|c|}{$\begin{array}{c}\text { CEEP in TWh/y at given percentage of demand covered by wind } \\
\text { power }\end{array}$} \\
\hline Scenario & $\begin{array}{l}\text { Hydrolog } \\
\text { y }\end{array}$ & $\begin{array}{l}10 \\
\%\end{array}$ & $\begin{array}{l}20 \\
\%\end{array}$ & $\begin{array}{l}30 \\
\%\end{array}$ & $\begin{array}{l}40 \\
\%\end{array}$ & $\begin{array}{l}50 \\
\%\end{array}$ & $\begin{array}{l}60 \\
\%\end{array}$ & $70 \%$ & $80 \%$ & $90 \%$ & $\begin{array}{c}100 \\
\%\end{array}$ \\
\hline \multirow{4}{*}{ Blue } & Dry & 0.12 & 0.53 & 1.27 & 2.57 & 4.27 & 6.21 & 8.25 & $\begin{array}{r}10.3 \\
0\end{array}$ & $\begin{array}{r}12.3 \\
7\end{array}$ & 14.44 \\
\hline & Normal & 0.39 & 1.02 & 2.04 & 3.40 & 5.10 & 7.06 & 9.15 & $\begin{array}{r}11.2 \\
7\end{array}$ & $\begin{array}{r}13.3 \\
9\end{array}$ & 15.51 \\
\hline & & & & & & & & 10.1 & 12.3 & 14.4 & \\
\hline & Wet & 0.85 & 1.73 & 2.93 & 4.37 & 6.1 & 8.05 & 6 & 2 & 9 & 16.65 \\
\hline \multirow{4}{*}{ Green } & Dry & 0.12 & 0.47 & 1.13 & 2.33 & 4.03 & 5.91 & 7.88 & 9.87 & $\begin{array}{r}11.8 \\
7\end{array}$ & 13.89 \\
\hline & Normal & 0.34 & 0.89 & 1.81 & 3.13 & 4.85 & 6.81 & 8.84 & $\begin{array}{r}10.9 \\
0\end{array}$ & $\begin{array}{r}12.9 \\
5\end{array}$ & 15.02 \\
\hline & & & & & & & & & 11.9 & 14.0 & \\
\hline & Wet & 0.75 & 1.52 & 2.66 & 4.10 & 5.83 & 7.79 & 9.86 & 7 & 8 & 16.18 \\
\hline \multirow{6}{*}{ White } & & & & & & & & & & 12.3 & \\
\hline & Dry & 0.12 & 0.53 & 1.27 & 2.57 & 4.27 & 6.21 & 8.25 & 10.3 & 7 & 14.44 \\
\hline & & & & & & & & & 11.2 & 13.3 & \\
\hline & Normal & 0.39 & 1.02 & 2.04 & 3.40 & 5.1 & 7.06 & 9.15 & 7 & 9 & 15.51 \\
\hline & & & & & & & & 10.1 & 12.3 & 14.4 & \\
\hline & Wet & 0.85 & 1.73 & 2.93 & 4.37 & 6.1 & 8.05 & 6 & 2 & 9 & 16.65 \\
\hline \multirow{3}{*}{ Wind } & Dry & 0.03 & 0.19 & 0.66 & 1.52 & 2.65 & 4.03 & 5.54 & 7.15 & 8.82 & 10.54 \\
\hline & Normal & 0.11 & 0.36 & 0.95 & 1.99 & 3.35 & 4.87 & 6.49 & 8.19 & 9.94 & 11.75 \\
\hline & Wet & 0.26 & 0.65 & 1.45 & 2.69 & 4.2 & 5.84 & 7.57 & 9.37 & 2 & 13.08 \\
\hline
\end{tabular}




\begin{tabular}{|c|c|c|c|c|c|c|c|c|c|c|c|}
\hline \multirow{4}{*}{ RES } & Dry & 0.08 & 0.32 & 0.92 & 1.96 & 3.27 & 4.76 & 6.36 & 8.05 & 9.79 & 11.59 \\
\hline & & 0.20 & 0.54 & 1.27 & 2.45 & 3.93 & 5.53 & 7.23 & 8.99 & $\begin{array}{r}10.8 \\
2\end{array}$ & 12.67 \\
\hline & & & & & & & & & 10.0 & 11.9 & \\
\hline & Wet & 0.39 & 0.91 & 1.85 & 3.18 & 4.72 & 6.42 & 8.21 & 4 & 1 & 13.8 \\
\hline \multirow{3}{*}{ Hydro } & Dry & 0.05 & 0.26 & 0.80 & 1.76 & 2.99 & 4.43 & 5.99 & 7.65 & 9.35 & 11.11 \\
\hline & Normal & 0.14 & 0.41 & 1.05 & 2.13 & 3.54 & 5.09 & 6.74 & 8.46 & $\begin{array}{r}0 \\
3\end{array}$ & 12.06 \\
\hline & Wet & 0.27 & 0.68 & 1.47 & 2.70 & 4.2 & 5.84 & 7.56 & 9.36 & 11.2 & 13.06 \\
\hline \multirow{6}{*}{ Replacement } & & & & & & & & & 11.0 & 13.2 & \\
\hline & Dry & 0.59 & 1.18 & 2.04 & 3.27 & 4.89 & 6.79 & 8.88 & 4 & 1 & 15.37 \\
\hline & & & & & & & & & 11.9 & 14.1 & \\
\hline & Normal & 1.02 & 1.76 & 2.80 & 4.12 & 5.76 & 7.67 & 9.77 & 6 & 9 & 16.4 \\
\hline & & & & & & & & & 11.2 & 13.4 & \\
\hline & Wet & 0.94 & 1.64 & 2.62 & 3.86 & 5.38 & 7.15 & 9.13 & 5 & 3 & 15.62 \\
\hline \multirow{4}{*}{$\begin{array}{l}\text { Slowed } \\
\text { build }\end{array}$} & Dry & 0.05 & 0.26 & 0.77 & 1.80 & 3.16 & 4.68 & 6.32 & 8.04 & 9.81 & 11.63 \\
\hline & Normal & 017 & 0.50 & 119 & 239 & 39 & 557 & 733 & 916 & $\begin{array}{r}11.0 \\
3\end{array}$ & 1293 \\
\hline & & & & & & & & & 10.4 & 12.3 & \\
\hline & Wet & 0.39 & 0.91 & 1.88 & 3.22 & 4.84 & 6.65 & 8.52 & 2 & 5 & 14.28 \\
\hline
\end{tabular}

In the second period, shown in Figure 10 the scenarios maintain the relations displayed before, with increased sensitivity in all scenarios due to the amount of new capacities installed according to scenarios. The aforementioned lower dependency of RES implementing scenarios is even more noticeable here, being the result of decommission of capacities according to Table 3, which provides more space for wind power. The complete results for the second period, including dry and wet hydrological conditions are given in Table 6.

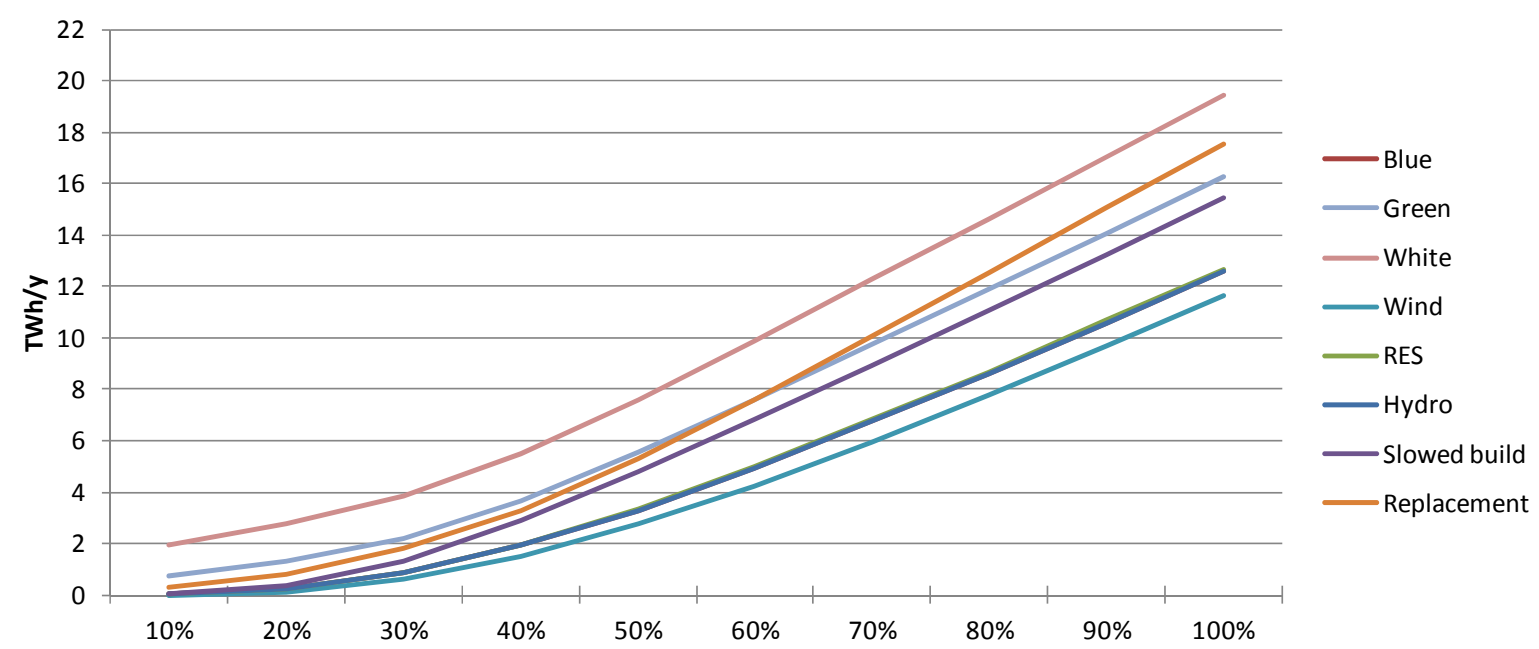

Figure 10 - Calculated CEEP for all scenarios and normal hydrology in 2030.

Results for different hydrological conditions mimic the results for normal hydrological conditions with slight changes in absolute values of CEEP, accounting for the changes in production from hydro power plants. 
Table 6 - Calculated CEEP for different scenarios and hydrological conditions in 2030.

\begin{tabular}{|c|c|c|c|c|c|c|c|c|c|c|c|}
\hline \multicolumn{2}{|c|}{2030} & \multicolumn{10}{|c|}{ CEEP in TWh/y at given percentage of demand covered by wind power } \\
\hline Scenario & $\begin{array}{c}\text { Hydrolog } \\
y\end{array}$ & $10 \%$ & $20 \%$ & $30 \%$ & $40 \%$ & $50 \%$ & $60 \%$ & $70 \%$ & $80 \%$ & $90 \%$ & $100 \%$ \\
\hline \multirow{6}{*}{ Blue } & & 0.0 & 0.3 & 1.1 & 2.6 & 4.6 & & & 12.0 & 14.5 & 17.1 \\
\hline & Dry & 4 & 2 & 5 & 8 & 6 & 6.94 & 9.42 & 0 & 8 & 4 \\
\hline & & 0.0 & 0.2 & 0.8 & 1.9 & 3.3 & & & & 10.5 & 12.6 \\
\hline & Normal & 3 & 3 & 5 & 2 & 0 & 4.95 & 6.74 & 8.63 & 9 & 0 \\
\hline & & 0.3 & 1.2 & 2.6 & 4.3 & 6.3 & & 11.1 & 13.7 & 16.4 & 19.1 \\
\hline & Wet & 9 & 7 & 2 & 4 & 6 & 8.64 & 4 & 6 & 4 & 1 \\
\hline \multirow{6}{*}{ Green } & & 0.4 & 0.8 & 1.6 & 3.0 & 4.8 & & & 10.8 & 13.0 & 15.1 \\
\hline & Dry & 0 & 1 & 3 & 7 & 5 & 6.78 & 8.80 & 8 & 0 & 5 \\
\hline & & 0.7 & 1.3 & 2.2 & 3.6 & 5.5 & & & 11.8 & 14.0 & 16.2 \\
\hline & Normal & 3 & 1 & 2 & 9 & 7 & 7.61 & 9.71 & 7 & 5 & 4 \\
\hline & & 1.1 & 1.8 & 2.8 & 4.3 & 6.3 & & 10.6 & 12.8 & 15.0 & 17.3 \\
\hline & Wet & 7 & 5 & 7 & 7 & 0 & 8.42 & 1 & 3 & 7 & 3 \\
\hline \multirow{6}{*}{ White } & & 1.3 & 2.1 & 3.1 & 4.7 & 6.8 & & 11.3 & 13.6 & 16.0 & 18.3 \\
\hline & Dry & 3 & 0 & 3 & 5 & 1 & 9.06 & 6 & 8 & 1 & 5 \\
\hline & & 1.9 & 2.7 & 3.8 & 5.5 & 7.5 & & 12.2 & 14.6 & 17.0 & 19.4 \\
\hline & Normal & 2 & 6 & 7 & 0 & 7 & 9.88 & 5 & 4 & 3 & 2 \\
\hline & & 2.5 & 3.5 & 4.7 & 6.4 & 8.4 & 10.8 & 13.2 & 15.6 & 18.1 & 20.5 \\
\hline & Wet & 8 & 1 & 5 & 2 & 8 & 1 & 3 & 8 & 1 & 5 \\
\hline \multirow{6}{*}{ Wind } & & 0.0 & 0.0 & 0.4 & 1.1 & 2.1 & & & & & 10.5 \\
\hline & Dry & 0 & 6 & 0 & 1 & 9 & 3.54 & 5.07 & 6.79 & 8.60 & 0 \\
\hline & & 0.0 & 0.1 & 0.6 & 1.5 & 2.7 & & & & & 11.6 \\
\hline & Normal & 1 & 3 & 1 & 2 & 6 & 4.24 & 5.94 & 7.76 & 9.65 & 2 \\
\hline & & 0.0 & 0.2 & 0.8 & 1.9 & & & & & 10.7 & 12.7 \\
\hline & Wet & 3 & 6 & 9 & 9 & 3.4 & 5.08 & 6.89 & 8.79 & 6 & 8 \\
\hline \multirow{6}{*}{ RES } & & 0.0 & 0.1 & 0.6 & 1.5 & 2.7 & & & & & 11.6 \\
\hline & Dry & 0 & 3 & 2 & 3 & 8 & 4.27 & 5.97 & 7.79 & 9.70 & 8 \\
\hline & & 0.0 & 0.2 & 0.8 & 1.9 & 3.3 & & & & 10.6 & 12.6 \\
\hline & Normal & 2 & 3 & 6 & 4 & 3 & 5.00 & 6.80 & 8.69 & 6 & 7 \\
\hline & & 0.0 & 0.4 & 1.1 & 2.4 & 4.0 & & & & 11.6 & 13.7 \\
\hline & Wet & 8 & 1 & 9 & 3 & 2 & 5.79 & 7.67 & 9.64 & 6 & 2 \\
\hline \multirow{6}{*}{ Hydro } & & 0.0 & 0.1 & 0.6 & 1.5 & 2.7 & & & & & 11.5 \\
\hline & Dry & 0 & 3 & 1 & 0 & 3 & 4.20 & 5.89 & 7.71 & 9.60 & 7 \\
\hline & & 0.0 & 0.2 & 0.8 & 1.9 & 3.3 & & & & 10.5 & 12.6 \\
\hline & Normal & 3 & 3 & 5 & 2 & 0 & 4.95 & 6.74 & 8.63 & 9 & 0 \\
\hline & & 0.0 & 0.4 & 1.2 & 2.4 & 4.0 & & & & 11.6 & 13.6 \\
\hline & Wet & 8 & 2 & 0 & 2 & 1 & 5.78 & 7.65 & 9.61 & 3 & 9 \\
\hline \multirow{6}{*}{$\begin{array}{c}\text { Replacemen } \\
\mathrm{t}\end{array}$} & & 0.1 & 0.4 & 1.1 & 2.5 & 4.4 & & & 11.6 & 14.0 & 16.4 \\
\hline & Dry & 2 & 5 & 9 & 5 & 9 & 6.74 & 9.16 & 0 & 5 & 9 \\
\hline & & 0.2 & 0.8 & 1.8 & 3.3 & 5.2 & & 10.0 & 12.5 & 15.0 & 17.5 \\
\hline & Normal & 8 & 1 & 1 & 1 & 8 & 7.58 & 4 & 5 & 5 & 4 \\
\hline & & 0.6 & 1.3 & 2.5 & 4.2 & 6.2 & & 11.0 & 13.5 & 16.1 & 18.6 \\
\hline & Wet & 0 & 8 & 7 & 3 & 4 & 8.52 & 0 & 5 & 0 & 3 \\
\hline
\end{tabular}




\begin{tabular}{|c|c|c|c|c|c|c|c|c|c|c|c|}
\hline \multirow{6}{*}{ Slowed build } & \multirow[b]{2}{*}{ Dry } & 0.0 & 0.2 & 1.0 & 2.4 & 4.0 & & & & 12.0 & 14.1 \\
\hline & & 1 & 1 & 2 & 0 & 7 & 5.95 & 7.94 & 9.98 & 6 & 9 \\
\hline & \multirow{3}{*}{ Normal } & 0.0 & 0.3 & 1.3 & 2.9 & 4.8 & & & 11.0 & 13.2 & 15.4 \\
\hline & & 6 & 9 & 4 & 3 & 2 & 6.82 & 8.92 & 5 & 2 & 4 \\
\hline & & 0.1 & 0.7 & 1.9 & 3.6 & 5.7 & & 10.0 & 12.2 & 14.5 & 16.8 \\
\hline & Wet & 7 & 3 & 2 & 7 & 0 & 7.84 & 2 & 7 & 3 & 0 \\
\hline
\end{tabular}

Calculations have also been made for open energy systems. The results of those calculations are somewhat similar to the ones presented earlier, but with a significant difference of experiencing CEEP no sooner than at $40 \%$ of demand covered by wind power in any of the scenarios, as can be seen in Figure 10 and Figure 11.

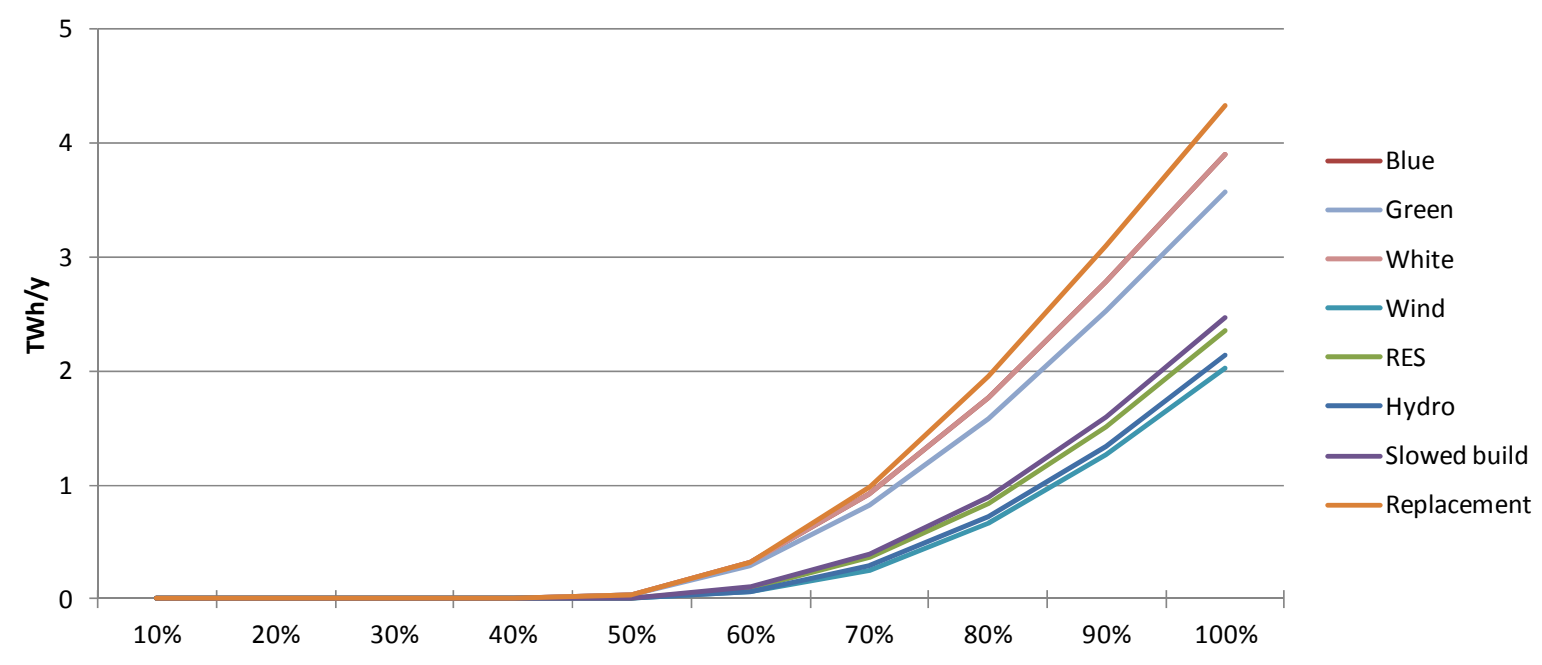

Figure 11 - Calculated CEEP in TWh/y for all scenarios and normal hydrological condition in 2020, open system.

This large difference can lead to a conclusion that the proposed systems could easily accept over $10 \%$ of demand covered by wind power plants with available exchange capacities, especially if considered that in a real system a power plant could be operated even below the minimum capacity selected in the model for a small period of time rather than compromising the grid.

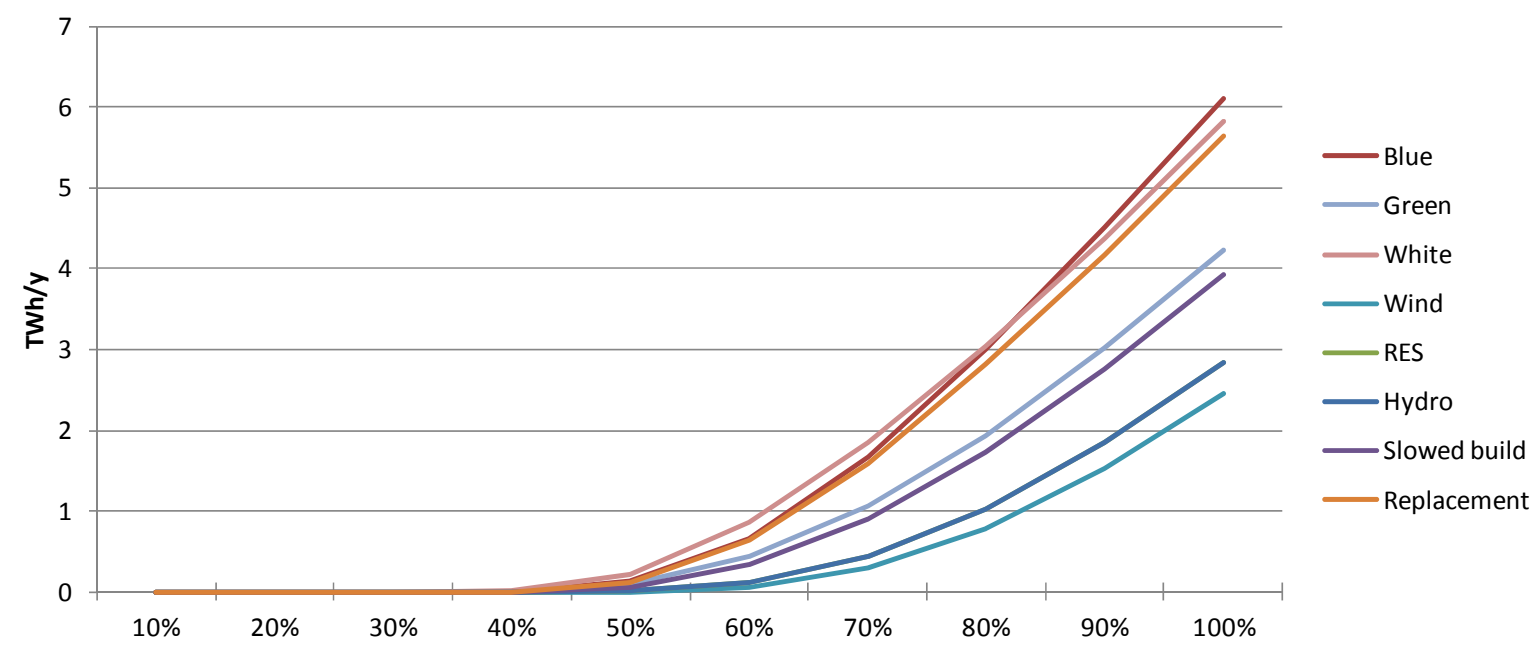


Figure 12 - Calculated CEEP in TWh/y for all scenarios and normal hydrological condition in 2030, open system.

\subsubsection{Import of electricity}

Regarding the import of electricity, results opposite to those in the case of CEEP can be expected. With the increase of installed wind power capacities, the need for import of electricity, and with it import dependency, decreases, as can been seen in Figure 13 and Figure 14.

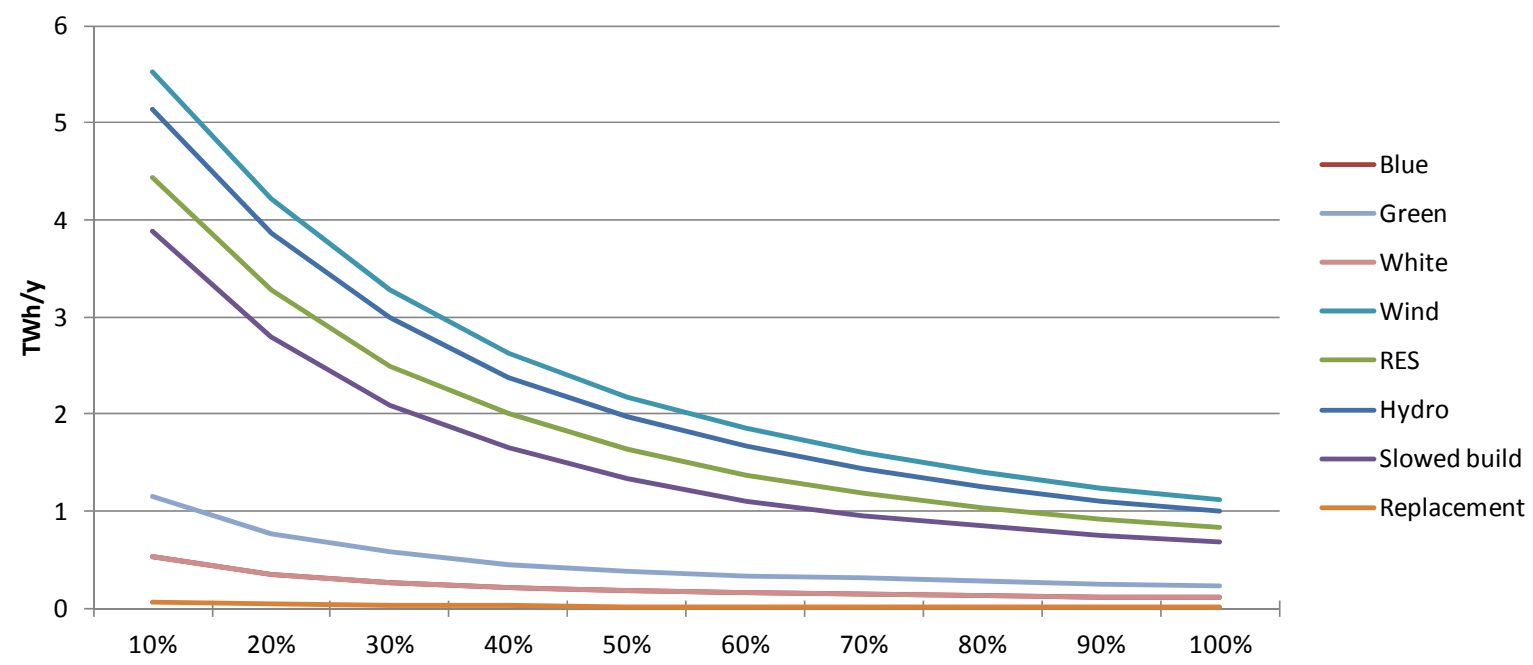

Figure 13 - Calculated import in $\mathrm{TWh} / \mathrm{y}$ for all scenarios and normal hydrological condition in 2020 .

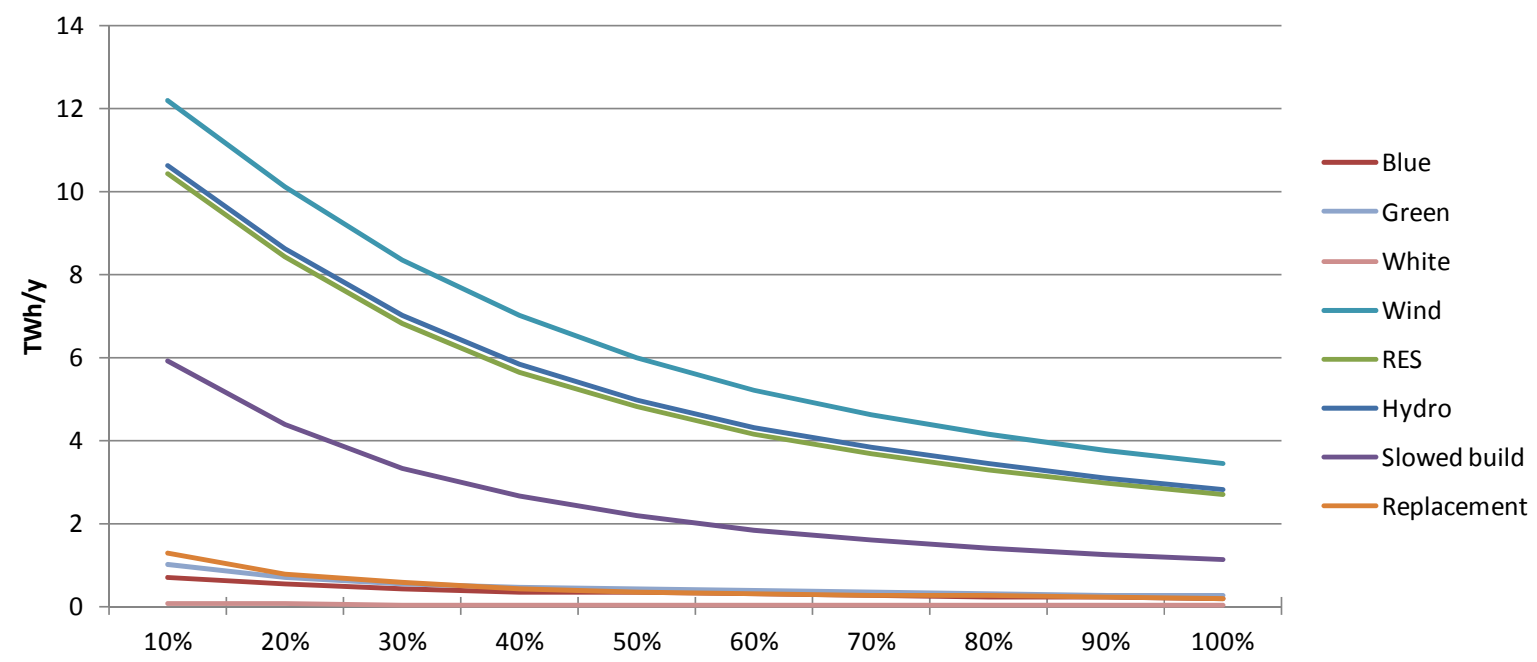

Figure 14 - Calculated import in TWh/y for all scenarios and normal hydrological condition in 2030 .

When studying the results above, it is necessary to remember that CEEP has been described as a dangerous and unwanted situation in electricity systems. Since the results have been calculated for open systems, results shall be valued up to $40 \%$ of demand covered by wind power in order to avoid CEEP in accordance to results shown in Figure 11 and Figure 12. 
Bearing that in mind, in the first period, electricity import can be significantly decreased by installing larger amounts of wind power plants. The decrease from import dependency of $42 \%$, or 7.82 TWh in the base year varies from $24.5 \%$ dependency achieved in the "Wind" scenario to $0.1 \%$ import dependency in the "Replacement" scenario, which equals a total import of 5.61 and $0.22 \mathrm{TWh} / \mathrm{y}$, respectively. In the results for the second period the impact of nuclear phaseout can be seen. In the case of "White" scenario and 10\% of demand covered by wind power the import dependency is 3\%, while scenarios with RES show a great increase in dependency compared to the first period, most notably in the "Wind" scenario with an increase to 53\% which decreases with increased penetration.

The results for other hydrological conditions exhibit some difference in absolute results due to different production from hydro power plants, but follow the same relations described above. Scenarios that implement RES start with greater import dependencies, especially after the phase-out of nuclear power, and therefore the effect of wind power penetration is more visible in those cases than in cases of conventional scenarios which cover most of the demand from planned capacities and achieve CEEP faster with additional wind power. Bearing in mind the behavior of those two groups of scenarios regarding CEEP, it can be concluded that while conventional power sources provide lower import dependency, their lower tolerance to wind penetration regarding CEEP suggest that systems using RES could be augmented by larger amounts of wind power plants, thus reducing import dependency while at the same time using the flexibility of RES to avoid CEEP.

\subsubsection{LDC of condensing power plants in conventional scenarios}

Scenarios which have large amount of conventional non-flexible power plants, such as "White", "Blue", "Green" and "Replacement", show a decrease of working hours on nominal capacity with the increase of electricity share covered by wind power plants.

Before analyzing the results in Figure 15 and Figure 16, some differences between these and traditional load duration curves should be explained. Since these curves study only a part of the system, namely condensing power plants, it is not possible to achieve one or few peak hours as is the case with classic LDC curves. Instead, as is logical to expect, the power plants shall operate on their nominal capacity for a larger number of hours per year. The curves in Figure 15 and Figure 16 shall depict the number of hours spent at nominal capacity, minimum capacity defined by the model and the values in between. By studying the number of hours at nominal and minimum capacity, feasibility of conventional power plants faced with increased penetration of wind power can be analyzed. 

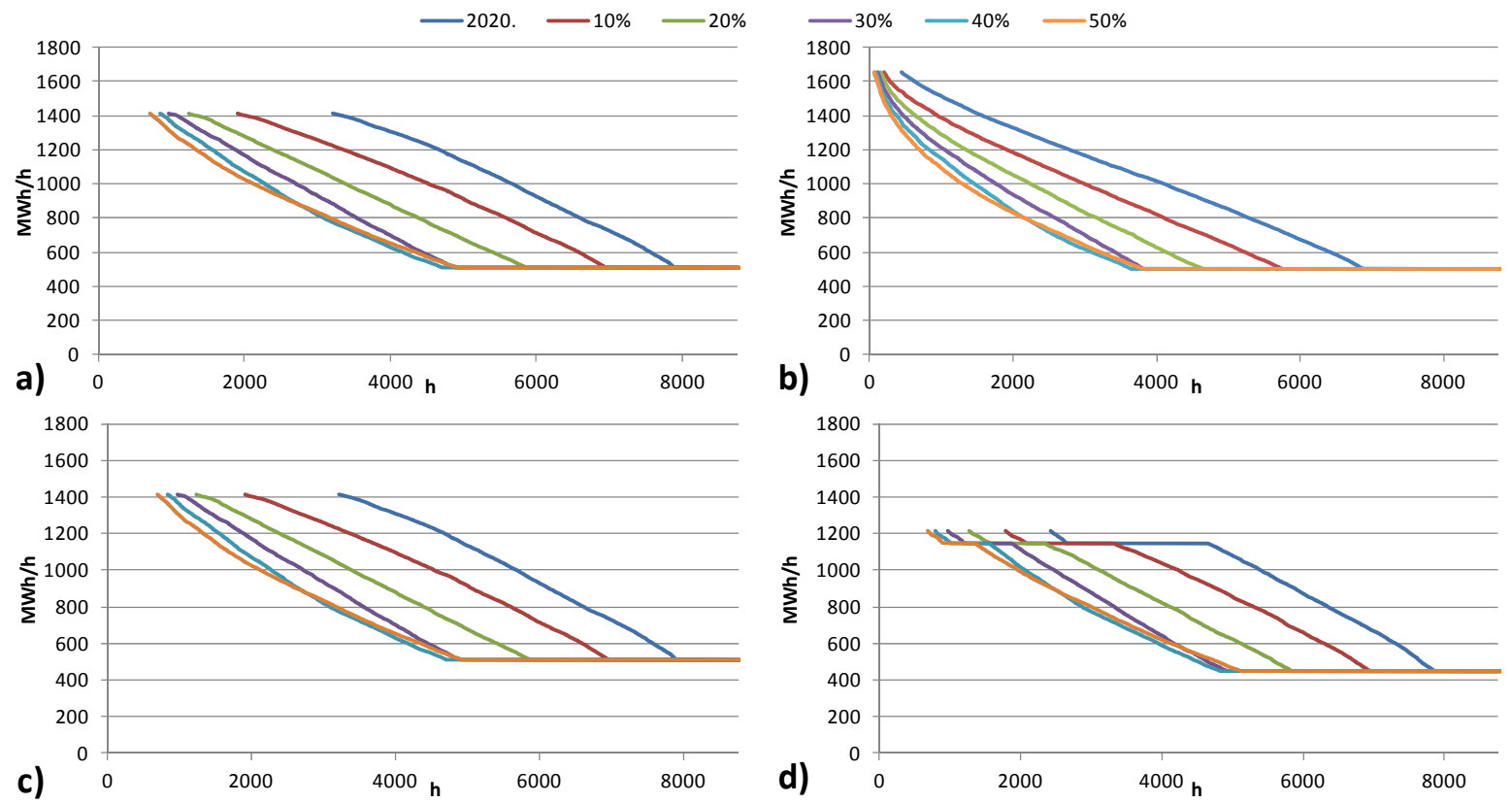

C) $\begin{array}{rrrr}0 & 2000 & 4000 \mathrm{~h} & 6000 \quad 8000\end{array}$

d)

Figure 15 - Load duration curves of condensing power plants for "White" (a), "Replacement" (b), "Blue"(c) and "Green" (d) scenario in 2020, normal hydrological sub-scenario.

In Figure 15, a set of LDC curves is shown for the "White" (a), "Replacement" (b), "Blue" (c) and "Green" (d) scenario in the year 2020, and year 2030 is presented in Figure 16. In each of the diagrams, the blue line represents the LDC of condensing power plants in the year 2020 or 2030 according to the unaltered scenario, described earlier. Then lines representing 10, 20, 30, 40 and $50 \%$ of the demand covered from wind power have been added. Results for penetration larger than $50 \%$ of the demand covered by wind haven't been studied, since the amount of wind power plants required for that percentage is roughly the same as the $4,3 \mathrm{GW}$ of wind power plant projects currently applied to Croatian Registry of RES projects (OIEKPP) [33]. 

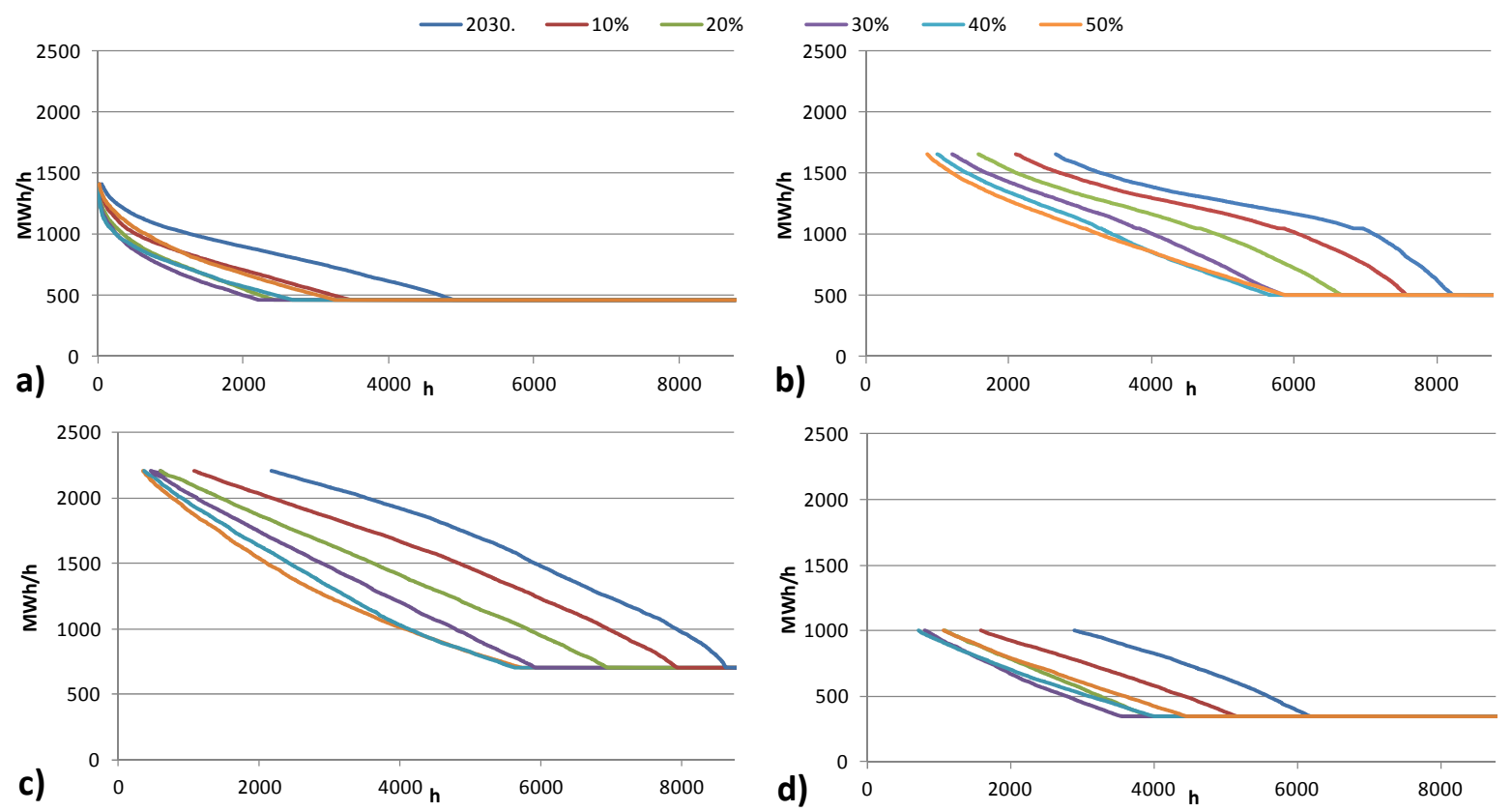

c)

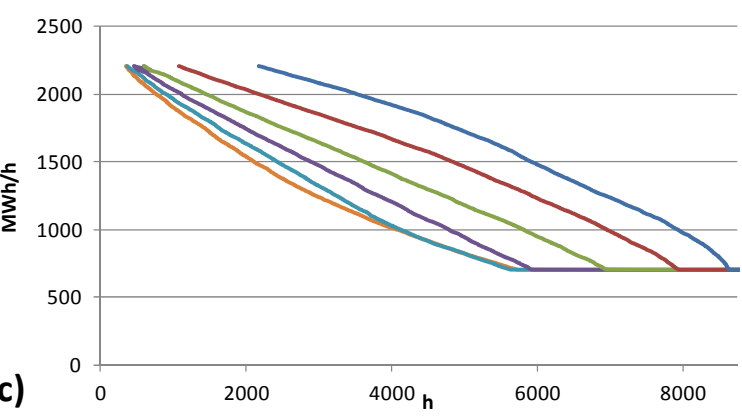

Figure 16 - Load duration curves of condensing power plants for "White" (a), "Replacement"

(b), "Blue"(c) and "Green" (d) scenario in 2030, normal hydrological sub-scenario.

In both periods, it is clearly visible that the curves are moving to the left, i.e. that the number of working hours at lower capacities is increasing. When comparing scenarios, the largest growth of working hours at minimum capacities is present in "White" and "Blue" scenario (because of the identical installation) in the first period with an increase of 3.6 time compared to base scenario.

At the same time, the mildest growth in the first period is present in the case of "Replacement" scenario, at 1.7 times more working hours at minimum capacity than in the case of base scenario. But, it also has to be noted that "Replacement" scenario has the largest absolute number of working hours compared to all the other scenarios and also note the extreme decrease of working hours at nominal capacity. This can be explained by the fact that the nominal system capacity remains the same trough replacement of the power plants and the old fuel oil power plants become operational when replaced with natural gas power plants which are acceptable to the market optimization model. This scenario can serve as an example what to expect from systems which are not flexible when faced with increased penetration of RES - in addition to increase of work hours on minimal capacity, a large decrease in work hours on nominal capacity is apparent, i.e. conventional power plants lose their share in demand covering.

The same behavior is present in the second period, in case of the "White" scenario. This can be expected since the scenario implements both coal and nuclear power in the system, which represents the most nonflexible technologies.

\section{CONCLUSION}

Eight scenarios for development of the Croatian energy system through different hydrological conditions and a high share of wind penetration were studied in this paper. Analyses were conducted in the EnergyPLAN model for the years 2020 and 2030. Electricity demand was 
obtained from the NeD model whose results show reduction in electricity consumption until 2030 compared to the Croatian Energy Strategy where electricity consumption has constant growth.

Results of the multi-scenario approach for Croatia, studied through technical, environmental and economic parameters, indicate that systems using conventional energy sources can achieve lower import dependence. However, to achieve lower $\mathrm{CO}_{2}$ emissions and to have decentralized energy production the share of renewable energy sources in the system would need to be greatly increased compared to present situation and with over $1200 \mathrm{MW}$ of wind until 2020 the Croatian Energy Strategy is going in that direction.

The impact of high share of renewable energy sources studied through CEEP and electricity import indicate that "Wind", "RES" and "Hydro" scenarios with a high share of RES show greater potential for implementation of intermittent energy sources in the system while "White", "Blue", "Green" and "Replacement" scenarios with a larger share of conventional and nonflexible power plants have more difficulty adjusting to wind power plants production. At the same time, the increase in wind power implementation in "White", "Blue", "Green" and "Replacement" scenarios has a serious impact on conventional power plants operation time which can be seen on their LDC curves. In case of large-scale penetration of wind in "White", "Blue", "Green" and "Replacement" scenarios, the feasibility of investing in new power plants that would spend most of the time working on minimum capacity is brought into question.

Considering results of analyses it can be seen that "Slowed build" scenario has good balance between import of electricity, $\mathrm{CO}_{2}$ emissions, investment costs and potential for implementation of intermittent energy sources in the system. Expanding "Slowed build" scenario with capacities considered in "RES" scenario and taking into account biomass potential of the country would lead to further decrease of import of electricity and $\mathrm{CO}_{2}$ emissions and at the same time to increase of security of supply and share of renewable energy. Furthermore, this expanded "Slowed build" scenario can be considered as a first step toward $100 \%$ renewable energy system of Croatia.

\section{Acknowledgment}

This work has been financially supported by Croatian Science Foundation under grant No. I4463-2011 (MICROGRID) and by the Croatian Science Foundation through project iRESEV (No. 09/128). This support is gratefully acknowledged.

\section{References}

[1] European Commission, EU Energy in figures - Statistical Pocketbook 2012, EU, Luxembourg, 2012, ISBN 978-92-79-22556-7.

[2] Directive 2009/28/EC of the European Parliament and of the Council, Official Journal of the European Union, 2009.

[3] Zervos A., Lins C., Muth J., Smith E., RE-thinking 2050: a 100\% renewable energy vision for the European Union, EREC - European Renewable Energy Council; 2010 
[4] Odenberger M., Johnsson F., Achieving 60\% $\mathrm{CO}_{2}$ reductions within the UK energy system-Implications for the electricity generation sector, Energy Policy, 35 (4) (2007), pp.2433-2452.

[5] Szklo A.S., Schaeffer R., Schuller M.E., Chandler W., Brazilian energy policies sideeffects on $\mathrm{CO}_{2}$ emissions reduction, Energy Policy, 33 (3) (2005), pp. 349-364

[6] Chua K.J., Yang W.M., Er S.S., Ho C.A., Sustainable energy systems for a remote island community, Applied Energy, 113 (2014), pp. 1752-1763.

[7] Bačelić Medić Z., Ćosić B., Duić N., Sustainability of remote communities: 100\% renewable island of Hvar, Journal of Renewable and Sustainable Energy, 5 (4) (2013), pp. 041806-1 - 041806-9.

[8] Østergaard P.A., Lund H., A renewable energy system in Frederikshavn using lowtemperature geothermal energy for district heating, Applied Energy, 88 (2) (2011), pp. 479-487.

[9] Shigeto S., Yamagata Y., Li R., Hidaka M., Horio M., An easily traceable scenario for $80 \% \mathrm{CO}_{2}$ emission reduction in Japan through the final consumption-based $\mathrm{CO}_{2}$ emission approach: A case study of Kyoto-city, Applied Energy, 90 (1) (2012), pp. 201-205.

[10] Wenjia C., Can W., Ke W., Ying Z., Jining C., Scenario analysis on $\mathrm{CO}_{2}$ emissions reduction potential in China's electricity sector, Energy Policy, 35 (12) (2007), pp. 6445-6456.

[11] Hickman R., Banister D., Looking over the horizon: Transport and reduced $\mathrm{CO}_{2}$ emissions in the UK by 2030, Transport Policy, 14 (5) (2007), pp. 377-387.

[12] Shimoda Y., Yamaguchi Y., Okamura T., Taniguchi A., Yamaguchi Y., Prediction of greenhouse gas reduction potential in Japanese residential sector by residential energy end-use model, Applied Energy, 87 (6) (2010), pp. 1944-1952.

[13] Lin B., Moubarak M., Mitigation potential of carbon dioxide emissions in the Chinese textile industry, Applied Energy, 113 (2014), pp. 781-787.

[14] Porzio G.F., Fornai B., Amato A., Matarese N., Vannucci M., Chiappelli L., et al., Reducing the energy consumption and $\mathrm{CO}_{2}$ emissions of energy intensive industries through decision support systems - An example of application to the steel industry, Applied Energy, 112 (2013), pp. 818-833.

[15] Mikulčić H., Vujanović M., Duić N., Reducing the $\mathrm{CO}_{2}$ emissions in Croatian cement industry, Applied Energy, 101 (2013), pp. 41-48.

[16] Lund H., Mathiesen B., Energy system analysis of 100\% renewable energy systems the case of Denmark in years 2030 and 2050, Energy, 34 (5) (2009), pp. 524-531.

[17] Krajačić G., Duić N., Zmijarević Z., Mathiesen BV, Anić-Vučinić A., Carvalho MG., Planning for a $100 \%$ independent energy system based on smart energy storage for integration of renewables and CO2 emissions reduction, Applied Thermal Engineering, 31 (13) (2011), pp. 2073-2083.

[18] Krajačić G., Duić N., Carvalho MG., How to achieve a 100\% RES electricity supply for Portugal, Applied Energy, 88 (2) (2011), pp. 466-472.

[19] Connolly D, Lund H, Mathiesen BV, Leahy M., The first step towards a 100\% renewable energy-system for Ireland, Applied Energy, 88 (2) (2011) 502-507. 
[20] Ćosić B., Krajačić G., Duić N., A 100\% renewable energy system in the year 2050: The case of Macedonia, Energy, 48 (2012), pp. 80-87.

[21] Irsag B., Pukšec T., Duić N., Long term energy demand projection and potential for energy savings of Croatian tourism-catering trade sector, Energy, 48 (1) (2012), pp. 398-405.

[22] Pukšec T., Mathiesen B., Duić N., Potentials for energy savings and long term energy demand of Croatian households sector, Applied Energy, 101 (2013), pp. 15-25.

[23] The Danish Government, Energy strategy 2050 - from coal, oil and gas to green energy, 2011

[24] German Federal Ministry of Economics and Technology, Germany's new energy policy - Heading towards 2050 with secure, affordable and environmentally sound energy, 2012

[25] Strategy for Renewable Energy: 2012-2020 [Internet], Irish Department of Communications, Energy and Natural Resources, Ireland, 2012, Available at: www.dcenr.gov.ie/NR/rdonlyres/9472D68A-40F4-41B8-B8FD-

F5F788D4207A/0/RenewableEnergyStrategy2012_2020.pdf [accessed 01.12.2013].

[26] Meeting the Energy Challenge - A White Paper on Energy [Internet], UK Department of Trade and Industry, UK, 2007, Available at: www.webarchive.nationalarchives.gov.uk/20121205174605/http:/www.decc.gov.uk/ assets/decc/publications/white_paper_07/file39387.pdf [accessed 01.12.2013].

[27] Laranja M., Portuguese National Strategy ENE 2020, www.norteemrede.inescporto.pt/planeamento-regional/informacaotransversal/recursos/pasta-apresentacoes-seminario2020/Microsoft\%20PowerPoint\%20-\%20ENE2020_ENGManuelLaranja.pdf [accessed 01.12.2013].

[28] Chaudhry N., Hughes L., Forecasting the reliability of wind-energy systems: A new approach using the RL technique, Applied Energy, 96 (2012), pp. 422-430.

[29] Shaw D., Cai J., Liu C., Efficiency analysis and controller design of a continuous variable planetary transmission for a CAES wind energy system, Applied Energy, 100 (2012), pp. 118-126.

[30] Liu W., Hu W., Lund H., Chen Z., Electric vehicles and large-scale integration of wind power - The case of Inner Mongolia in China, Applied energy, 104 (2013), pp. 445-456.

[31] Ma T., Yang H., Lu L., A feasibility study of a stand-alone hybrid solar-wind-battery system for a remote island, Applied Energy, 121 (2014), pp. 149-158.

[32] Green Paper-Update/Upgrade of the Energy Strategy and of the Implementation Programme of the Republic of Croatia [Internet], Ministry of Economy, Labour and Entrepreneurship, Republic of Croatia \& United Nations Development Program, Zagreb, Croatia, 2008, Available at: www.mingo.hr/userdocsimages/Green\%20Paper\%20Energy.pdf [accessed 01.12.2013].

[33] Registry of renewable energy sources, cogeneration and feed-in production plants and projects - OIEKPP [Internet] Ministry of Economy Labour and Entrepreneurship, Croatia, 2013, Available at: www.oie.mingo.hr [accessed 01.12.2013]. 
[34] Ministry of Economy Labour and Entrepreneurship, Energy in Croatia - Annual Energy Report - 2009, Zagreb, Croatia, 2010.

[35] ENTSO-E, www.entsoe.eu [accessed 01.12.2013].

[36] Indicative mid-term development plan (In Croatian) [Internet], HEP Transmission System Operator, Croatia, 2011, Available at: www.hep.hr/ops/hees/HEP_OPS_sred_plan_razvoja.pdf [accessed 01.12.2013].

[37] EnergyPLAN: Advanced energy system analysis computer model, Aalborg University, Denmark, Available at: www.energy.plan.aau.dk (version 9.0).

[38] Liu W., Lund H., Mathiesen B., Large-scale integration of wind power into the existing Chinese energy system, Energy, 36 (8) (2011), pp. 4753-4760.

[39] Gota D., Lund H., Miclea L., A Romanian energy system model and a nuclear reduction strategy, Energy, 36 (11) (2011), pp. 6413-6419.

[40] Zhai P., Larsen P., Millstein D., Menon S., Masanet E., The potential for avoided emissions from photovoltaic electricity in the United States, Energy, 47 (1) (2012), pp. 443-450.

[41] Lund H., Andersen AN., Optimal designs of small CHP plants in a market with fluctuating electricity prices, Energy Conversion and Management, 46 (6) (2005), pp. 893-904.

[42] Lund H., EnergyPLAN - advanced energy system analysis computer model, users manual documentation version 9.0., Aalborg, Denmark: Aalborg University, 2011.

[43] Pukšec T., Mathiesen BV, Novosel T., Duić N., Assessing the impact of energy saving measures on the future energy demand and related GHG emission reduction of Croatia, Energy (2014), 10.1016/j.energy.2014.06.045.

[44] Pavković D., Pukšec T., Duić N., Energy demand modelling for the Croatian education sector, Proceedings of the 21st International symposium on heating, refrigerating and air conditioning, 07-08 April 2011, Zagreb, Croatia.

[45] Pukšec T., Krajačić G., Lulić Z., Mathiesen B.V., Duić N., Forecasting long-term energy demand of Croatian transport sector, Energy, 57 (2013), pp. 169-176.

[46] Bačelić Medić, Z., Pukšec T., Mathiesen B.V., Duić N., Modelling energy demand of Croatian industry sector, International Journal of Environment and Sustainable Development, 13 (1) (2014), pp. 74-92.

[47] Duić N., Krajačić G., Pukšec T, Ćosić B., Novosel T., Ridjan I., Renewable Energy Sources, Energy Efficiency and Reduction of Greenhouse Gas Emissions as main sources of Development of „Green Economy“ in Croatia until 2050, Zagreb, Croatia 2012.

[48] HEP: www.hep.hr/proizvodnja [accessed 01. 12. 2013].

[49] International Energy Agency (IEA), Energy statistics for Croatia in 2009, 2009.

[50] International Energy Agency (IEA), Energy in the Western Balkans - The Path to Reform and Reconstruction. IEA, Paris, France, 2008.

[51] Bajs D., Development of Croatian electroenergetic system until the year 2030 (MASTERPLAN), book 3 - Transport grid, EIHP, Zagreb, 1998.

[52] Technology Data for Energy Plants [Internet]. Danish Energy Agency, Copenhagen, Denmark, 2010, Available at: www.energinet.dk/SiteCollectionDocuments/Danske\%20dokumenter/Forskning/Tec 
hnology_data_for_individual_heating_plants_and\%20energy_transport.pdf [accessed 01. 12. 2013].

[53] Ćosić B., Stanić Z., Duić N., Geographic distribution of economic potential of agricultural and forest biomass residual for energy use: case study Croatia, Energy, 36 (4) (2011), pp. 2017-2028. 